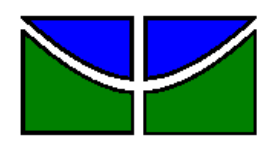

Universidade de Brasília

Faculdade de Economia, Administração, Contabilidade e Ciências da Informação e Documentação

DEPARTAMENTO DE ADMINISTRAÇÃO

TRABALHO DE CONCLUSÃO DE CURSO

MODELAGEM DE PROCESSOS: GAP CONCEITUAL QUANTO AO NÍVEL IDEAL DE DETALHAMENTO DE PROCESSO

Vítor Bizinoto dos Santos Anjo

Brasília - DF

Julho / 2009 
Universidade de Brasília

Faculdade de Economia, Administração, Contabilidade e Ciências da Informação e Documentação

DEPARTAMENTO DE ADMINISTRAÇÃO

TRABALHO DE CONCLUSÃO DE CURSO

\section{MODELAGEM DE PROCESSOS: GAP CONCEITUAL QUANTO AO NÍVEL IDEAL DE DETALHAMENTO DE PROCESSO}

Vítor Bizinoto dos Santos Anjo

\section{Professor Orientador: Guilherme Arruda, Especialista}

"Trabalho apresentado em cumprimento às exigências acadêmicas parciais da disciplina Estágio Supervisionado em administração para a obtenção do grau de Administrador”

Brasília - DF

Julho / 2009 
Anjo, Vítor Bizinoto dos Santos

Modelagem de Processos: GAP conceitual quanto ao nível ideal de detalhamento de processo / Vítor Bizinoto dos Santos Anjo. Brasília, 2009.

50f. : il.

Monografia - Universidade de Brasília, Departamento de Administração, 2009.

Orientação: Prof. Guilherme Arruda, Departamento de Administração.

1. Gestão de Processos. 2. Modelagem de Processos. 3. Prestação de Serviços. I. Título. 


\title{
MODELAGEM DE PROCESSOS: GAP CONCEITUAL QUANTO AO NÍVEL IDEAL DE DETALHAMENTO DE PROCESSO
}

A Comissão Examinadora, abaixo identificada, aprova o Trabalho de Conclusão do Curso de Administração da Universidade de Brasília do aluno:

\section{Vítor Bizinoto dos Santos Anjo}

\author{
Guilherme Arruda, Especialista \\ Professor-Orientador \\ Delciene Pereira \\ Professora-Examinadora
}

Brasília, 09 de julho de 2009. 


\section{RESUMO}

A partir do destaque da Gestão de Processos como ferramenta capaz de auxiliar as organizações a uma maior eficiência operacional, o número de iniciativas em gestão de processos por parte das organizações tem crescido significativamente, demandando, por consequiência, serviços especializados na área. Diante do contexto da prestação de serviços em modelagem de processos, existe o gap de entendimento entre consultorias especializadas e organizações clientes quanto ao nível ideal de detalhamento de processo. O não alinhamento entre as duas partes quanto ao nível desejado pode ocasionar o não cumprimento das expectativas da organização cliente quanto aos serviços prestados, pois ora os processos fluxogramados omitem informações, ora excedem a quantidade de informações necessárias. Diante deste cenário, o presente trabalho objetivou a análise dos impactos desse gap, bem como as causas de sua ocorrência, diante do estudo de caso referente à prestação de serviço de mapeamento de processos no Departamento de Engenharia de Telecomunicações de Furnas Centrais Elétricas. Através de pesquisa qualitativa, foram levantadas as percepções dos envolvidos no projeto quanto à ocorrência do gap. O resultado obtido no trabalho apresenta que as causas da ocorrência do gap estão relacionadas a não definição no Edital de contratação do nível de detalhamento, a falta de ação durante o projeto para a validação dos níveis gerados, a falta de conhecimento dos envolvidos no projeto quanto às especificidades dos processos e a subjetividade do nível de detalhamento determinado. Quanto aos impactos, estão relacionados a falta de uniformidade dos fluxos gerados pelo mapeamento dos processos, a influência dos entrevistados no nível de detalhamento dos processos, a dificuldade no dimensionamento do projeto por parte da consultoria especializada e a falta de aderência de alguns fluxos de processos com a realidade. Percebeu-se, por fim, que saber lidar com esse problema permite uma maior convergência de esforço de todos os envolvidos em um projeto para o alcance dos objetivos da modelagem.

Palavras chave: Gestão de Processos, Modelagem de Processos, Detalhamento de Processos, $G A P$, Prestação de Serviço, Consultoria. 


\section{SUMÁRIO}

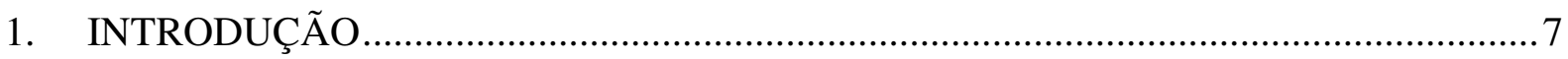

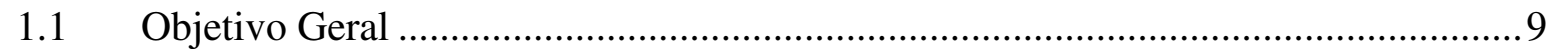

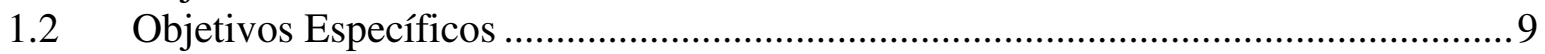

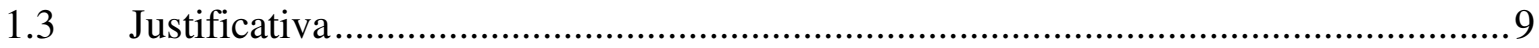

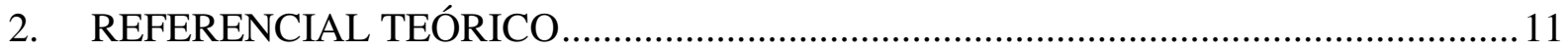

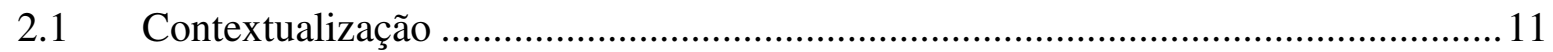

2.2 Histórico da Racionalização do Trabalho............................................................ 12

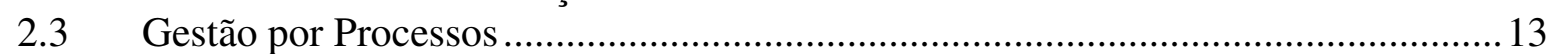

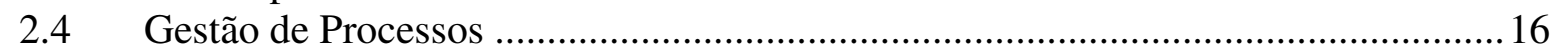

2.5 Conceituação sobre Processos ........................................................................ 17

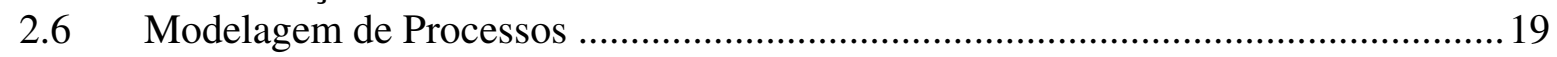

2.6.1 Objetivos, Motivações e Benefícios da Modelagem de Processos.....................20

2.6.2 Princípios da Modelagem de Processos ............................................................... 21

2.6.3 Métodos de Modelagem de Processos.............................................................. 21

2.6.4 Níveis de Detalhamento na Modelagem de Processos ........................................22

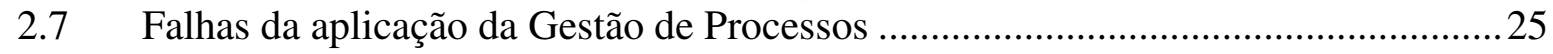

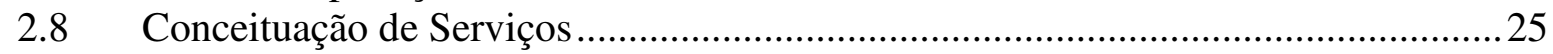

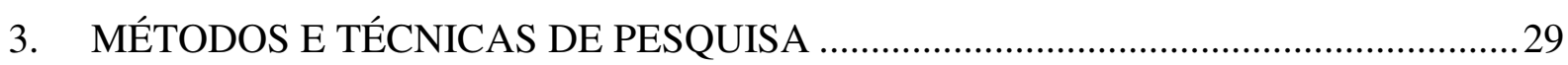

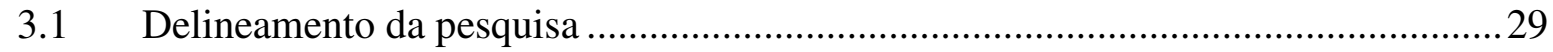

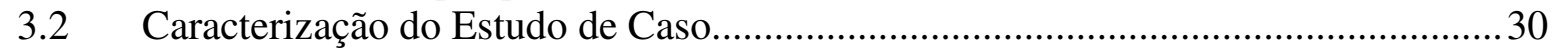

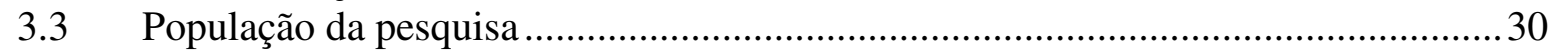

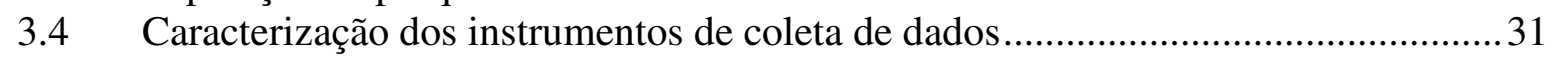

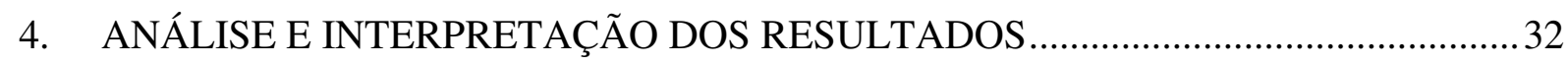

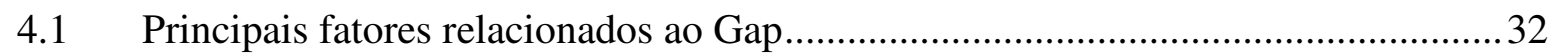

4.2 O edital de licitação referente à contratação da consultoria especializada.................33

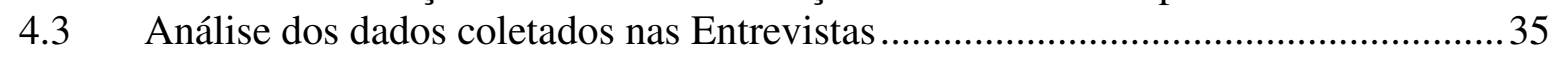

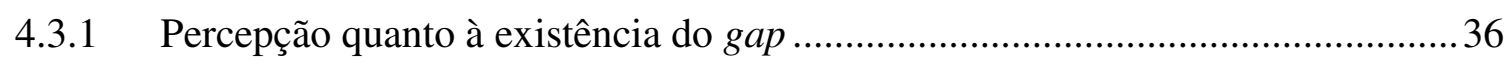

4.3.2 Motivos e Impactos do gap segundo percepção dos entrevistados .....................36

4.3.3 Motivações para a realização e elaboração do projeto ........................................ 37

4.3.4 Definição do nível de detalhamento dos processos ............................................ 38

4.3.5 Esclarecimento quanto à metodologia e resultados esperados do projeto............38

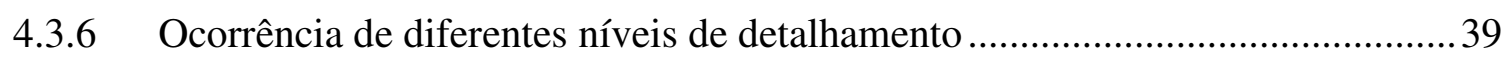

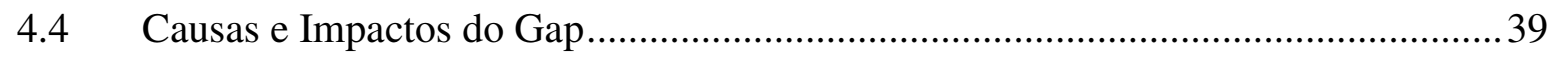

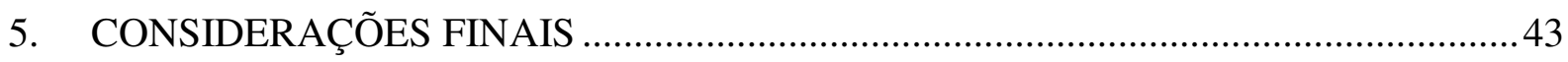

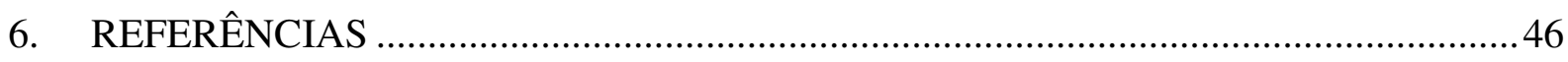

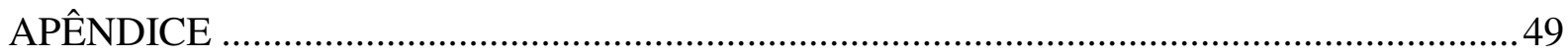




\section{INTRODUÇÃO}

Qualquer atividade importante realizada dentro de uma organização está inserida em algum processo operacional e qualquer produto ou serviço prestado por essa organização é necessariamente resultado de um desses processos (GRAHAM \& LEBARON, 1994). Tomando como base que toda organização é formada por um conjunto de processos distintos (GONÇALVES, 2000a), é extremamente necessário que as organizações executem seus processos de forma balanceada através da gestão dos processos, para assim atingir seus objetivos (ALMEIDA, 2002).

Considerando as organizações como sistemas abertos, as mudanças ambientais de diferentes ordens afetam os padrões de competitividade empresarial e precisam ser consideradas no processo de tomada de decisão estratégica das organizações. Com isso, estimula-se que as organizações busquem a eficiência em seus aspectos operacionais como forma de se tornarem competitivas, mesmo não sendo o conceito de competitividade apenas um sinônimo de eficiência ou desempenho (SILVA \& BARBOSA, 2002).

Dentro desse contexto competitivo, a fim de buscar a eficiência operacional, os modelos burocráticos de gestão possuem limitações, pois estão baseados numa gestão funcional focada na especialização e na delegação da coordenação para a hierarquia, tornando as organizações pouco flexíveis. Em contrapartida, a gestão de processos permite as organizações modernas atuarem de forma ágil, integrada e flexível, adaptando-se ao novo cenário competitivo e dinâmico. A gestão de processos, assim, tornou-se um conceito e uma ferramenta gerencial de destaque (PAIM et al., 2007).

A partir desse princípio, muitas organizações, tanto privadas, quanto públicas, passaram a enxergar a gestão de processos como essencial para um bom desempenho organizacional e iniciaram esforços visando à implementação desse conceito. Porém, segundo Paim (2002, p. 248) "os conceitos de processos ainda são poucos difundidos ou mal entendidos nas Organizações apesar de estas estarem, desde a década passada, investindo significativamente na orientação por processos." Evidencia-se, assim, uma dificuldade a ser enfrentada por elas.

Por consequiência das iniciativas de se investir em processos, somadas a falta de conhecimentos específicos para conduções de trabalhos nessa área, percebe-se o surgimento da demanda, por parte dessas organizações, por serviços de consultoria especializados em gestão de processos. Esses serviços, em sua grande maioria, estão relacionados à Modelagem 
de Processos, sendo esta uma das principais ferramentas que suportam a Gestão de Processos (PAIM, 2002). O escopo base desses serviços especializados, independentemente de seu propósito, gira em torno do levantamento dos processos operacionais da organização, seguido por propostas de melhoria para esses processos, gerando assim manuais de procedimentos para o executor do processo.

Por se tratar de prestação de serviço, esta que é uma atividade profundamente interativa com alto nível de contato interação entre consumidores e usuários (MEIRELLES, 2006), há uma série de peculiaridades que a diferenciam da produção de bens. Ou seja, a prestação de serviços possui dificuldades e procedimentos essencialmente diferentes do outro grupo, como por exemplo, a dificuldade de demonstração dos produtos que serão realizados antecipadamente (MILES, 1983).

Diante do contexto da prestação de serviços por parte de consultorias especializadas em modelagem de processos para organizações demandantes, existem gaps conceituais entre essas duas partes quanto à natureza do serviço que podem impactar diretamente no seu sucesso. Esses gaps permeiam não só o alinhamento dos prazos e custos dos serviços, mas também o alinhamento das metodologias a serem utilizadas, dos conceitos técnicos envolvidos, dos resultados esperados, entre outros.

Um gap conceitual que possui alta ocorrência de casos está relacionado com a abrangência da modelagem de processos, mais estritamente com o nível de detalhamento do processo utilizado como base para a realização da modelagem. Em diversas ocasiões, os serviços de modelagem não conseguem satisfazer a organização demandante, pois o processo oculta informações ou excede a quantidade de informações necessárias. A consultoria pode, porém, julgar que o resultado atingido estava de acordo com os pressupostos estabelecidos para a modelagem, estes, que por sua vez, podem estar com viés técnico metodológico, e não relacionado à realidade operacional do processo.

Por falta desse alinhamento, clientes e consultorias entram em um processo desgastante de discussões a respeito do serviço prestado. De um lado, clientes insatisfeitos reclamam que o produto final de determinado trabalho não está de acordo com o demandando, relatam que o produto final pode não ser útil. Baseiam-se no que julgam necessário para a operação de seus processos. Do outro lado, empresas de consultoria se defendem alegando que o trabalho executado realmente cumpriu com o estabelecido, expõem que o trabalho executado foi concluído de acordo com o demandado. Baseiam-se nos preceitos conceituas estabelecidos para a realização do serviço. 
Diante desse cenário, chega-se ao seguinte questionamento: Quais são os impactos causados pelo gap de entendimento entre consultorias especializadas e organizações clientes quanto ao nível ideal de detalhamento na modelagem de processos?

\subsection{Objetivo Geral}

O presente trabalho tem como objetivo geral identificar os impactos causados pelo gap de entendimento entre consultorias especializadas e organizações clientes quanto ao nível ideal de detalhamento na modelagem de processos considerando como estudo de caso o projeto realizado no Departamento de Telecomunicações de Furnas Centrais Elétricas.

\subsection{Objetivos Específicos}

Este projeto de monografia pretende atingir os seguintes objetivos:

1. Levantar e analisar, através da pesquisa em campo, os dados referentes à condução de um projeto de modelagem de processos realizado no Departamento de Telecomunicações de Furnas Centrais Elétricas, focando nos fatores relacionados à problemática desse trabalho.

2. Comparar dados levantados na pesquisa do estudo de caso com os dados secundários levantados nas literaturas afins;

3. Identificar quais são as causas do gap de entendimento referente ao objeto deste trabalho;

4. Identificar quais são os impactos causados pelo gap de entendimento referente ao objeto deste trabalho;

\subsection{Justificativa}

Qualquer que seja a natureza de uma prestação de serviço, esta deve se adequar às especificações quando às características do produto e ao próprio processo de produção (MILES, 1983).

As principais causas das falhas para a implementação da Gestão de Processos, segundo Paim (2002), estão relacionadas a: Necessidade de Conhecimento; Gestão da 
Mudança e do Projeto; Má definição de escopo; Falta ou Planejamento inadequado; Falta de comunicação; e Falta de preparação.

O presente trabalho, como já apresentado, pretende analisar um problema que aborda algumas das principais causas de falhas de um trabalho de modelagem de processos, estes pouco abordados nas literaturas encontradas. Pode-se perceber que o gap conceitual quanto ao nível ideal de detalhamento está relacionado com: especificação de serviço do consumidor, necessidade de conhecimento, má definição do escopo e falta de comunicação.

Conhecer as causas e os impactos desse gap permite que as organizações clientes e as consultorias especializadas façam o alinhamento necessário para que o projeto atenda as reais necessidades de seus fatores motivadores, e por conseqüência, atinja o sucesso esperado entre as partes.

Permite, também, que as consultorias especializadas dêem continuidade ao ciclo de melhoria contínua, a partir de lições aprendidas, tendo em vista que o entendimento dos causadores do problema faz com que, a cada novo projeto, este problema seja minimizado, ou até mesmo, eliminado. 


\section{REFERENCIAL TEÓRICO}

A fundamentação de um trabalho científico consiste, segundo Tomanik (1994), na etapa em que os conhecimentos teóricos, a respeito do tema envolvido, são aprofundados. Sendo assim, este referencial teórico tem como objetivo apresentar os principais conceitos que envolvem a gestão e modelagem de processos e apresentar referências que conceituam serviços.

O presente referencial teórico está dividido em sete principais itens:

Contextualização; (2) Histórico da racionalização do trabalho: aborda o histórico de filosofias da administração que influenciaram na atual abordagem de processos (3) gestão por processos: apresenta conceituação do tema abordando suas principais características; (4) gestão de processos: aborda seus conceitos e os principais objetivos de sua aplicação; (5) conceituação sobre processos: apresenta a definição de processo e suas características (6) modelagem de processos: abordagem da principal ferramenta da gestão de processo apresentando seus principais objetivos, princípios, métodos e nível de detalhamento; (7) falhas da aplicação da Gestão de Processos: apresenta algumas das principais causas de falhas de sua aplicação; (8) Conceituação de serviços: apresenta as características peculiares do setor de serviços.

\subsection{Contextualização}

Como conseqüência da nova e crescente competitividade global, as empresas têm sido forçadas a melhorar seu desempenho, reavaliando os valores para os clientes e estruturando suas operações de forma sistêmica e integrada. Essas transformações no panorama competitivo têm apontado para a necessidade tanto de agilidade nas mudanças quanto de novos conceitos e práticas de gestão. Estes elementos estão se tornando cada vez mais vitais, tanto para garantir a sobrevivência, como para um diferencial competitivo das organizações (NETTO, 2006).

No momento da tomada de decisão, segundo (NETTO, 2006) o cliente passa a avaliar o resultado das operações das empresas com maior grau de exigência a questões relacionadas à qualidade do produto (bem, serviço ou informação), ao processo, ao sistema e a organização. $\mathrm{O}$ cliente, em última na análise, tem buscado as características que diferenciam 
os seus possíveis fornecedores, e conseqüentemente, deles exigido melhoria nos processos organizacionais (NETTO, 2006).

Em contra mão a essa necessidade de adaptação, grande parta das organizações possui sua estrutura e administração baseada em fundamentos que analisam ou entendem as coisas em partes separadas. Por consequiência, se estruturam em uma visão departamental, levando pouco em consideração sua visão sistêmica. Isso dificulta, portanto, sua comunicação interdepartamental e interfuncional, tornando-as pouco eficientes (BEDUSCHI, 2004). Segundo Martin (1996, apud Beduschi, 2004), grande parte desse problema é decorrente do fato que as estruturas gerenciais e os processos de trabalho dessas organizações terem sido desenhados há décadas.

A partir dessas necessidades de adaptação das organizações, a prática de gestão baseada em conceitos de processos ganhou bastante destaque como ferramenta capaz de atender a essas necessidades (NETTO, 2006; PAIM, 2002). De modo inclusivo, várias são as abordagens modernas de gestão que se apóiam nesses conceitos (NETTO, 2006).

Antes da análise da gestão por processos, é apresentado o histórico das práticas de gestão que visavam a racionalização do trabalho, estas que influenciaram significativamente na abordagem da gestão de processos.

\subsection{Histórico da Racionalização do Trabalho}

Segundo Valle e Peixoto (2006), podemos dividir as tentativas de Racionalização do Trabalho como gerações, entre as quais há tanto continuidade, quanto rupturas. Estas gerações vão desde as proposta dos clássicos da administração a propostas do TQC (Total Quality Control).

A primeira geração da Racionalização do Trabalho é baseada nos autores clássicos da Engenharia da Produção, como Taylor, Ford e Fayol, que buscava, em suma, apoio na racionalidade do trabalhador. Segundo Valle e Peixoto (2006), ela se baseavam em cinco princípios: análise científica e posterior padronização das tarefas; seleção científica de trabalhadores aptos a executarem as tarefas, treinamento dos trabalhadores selecionados; motivação exclusivamente salarial; e cooperação entre trabalhadores e direção da empresa.

A segunda geração da Racionalização do Trabalho, apresentada por Valle e Peixoto (2006), está baseada numa outra visão da racionalidade humana. Num momento em que a 
psicologia começava a se vulgarizar nos Estados Unidos, um Grupo de Harvard sugeriu que os gerentes apelassem nem tanto para o lado racional, mas, sobretudo, para motivações em partes inconscientes. Nessa geração, a chamada escola das Relações Humanas propôs que os gerentes abandonassem o autoritarismo e passassem a considerar a situação social de trabalho como forma de compensar os efeitos negativos do trabalho e por consequiência o aumento de produtividade por parte desses trabalhadores.

Do ponto de vista histórico segundo Valle e Peixoto (2006), a segunda geração não substitui a primeira, mas apenas a complementou, fazendo com que os fatores humanos entrassem nas preocupações cotidianas dos supervisores das fábricas

Como terceira geração da Racionalização do Trabalho, encontra-se o modelo japonês da qualidade (TQC, Kanban, CCQ, etc.) que se impôs como alternativa a outras gerações. Este modelo não significa uma ruptura completa com as formas anteriores de Racionalização do Trabalho, mas se diferencia principalmente no grau de separação entre tarefas manuais e intelectuais, uma vez que passam a ser aceitas sugestões dos trabalhadores na análise das tarefas e são introduzidas medidas no intuito de reduzir a centralização provocada pela racionalização da primeira geração. (VALLE \& PEIXOTO, 2006).

\subsection{Gestão por Processos}

Em estudo realizado por Martin com 200 empresas americanas (1996, apud BEDUSCHI, 2004), identificou-se um investimento bastante significativo por parte dessas empresas em reestruturação organizacional. Influenciadas por mudanças tecnológicas e por um ambiente globalizado de competição, tornou-se necessário o redesenho das funções organizacionais exercidas pela maioria das pessoas. Esse redesenho aparece como uma forma de adequar as pessoas e as organizações às novas realidade do mercado, visando, assim, o aumento de sua competitividade e do seu valor organizacional (GATES, 1999 apud BEDUSCHI, 2004).

Baseando-se nos valores e objetivos organizacionais, o redesenho das funções cria a necessidade de se reformular as estruturas gerenciais ultrapassadas por meio da reinvenção dos seus processos de negócio. Com isso, as organizações acentuaram o interesse nos seus processos devido a sua importância para o desenvolvimento de uma organização inovadora e competitiva em ambientes turbulentos. Dessa forma, em um curto espaço de tempo, 
proliferou-se no mercado metodologias, técnicas e ferramentas destinadas a gestão por processos (BEDUSCHI, 2004).

Segundo Netto (2006), os primeiros trabalhos enfocando a Gestão por Processos datam da primeira metade da década de 80 . Aborda também que ela não nasceu pronta como fruto de teoria e pesquisa acadêmica e segundo o autor, existem diversos nomes utilizados para o tema. O termo Gestão por Processos, segundo Netto (2006) foi consolidado a partir da criação da reengenharia por Hammer em 1990.

Entre as diversas conceituações encontradas por Netto (2006), a gestão por processos pode ser entendida como enfoque de desenvolvimento organizacional que tipicamente busca alcançar melhorias qualitativas de desempenho nos processos, tomando uma visão objetiva e sistêmica das atividades, estruturas e recursos necessários para cumprir os objetivos críticos do negócio. Sendo assim, o autor propõe a seguinte conceituação para gestão por processos:

Gestão por processos é o enfoque sistêmico de projetar e melhorar continuamente os processos organizacionais, por pessoas potencializadas e trabalhando em equipe, combinando capacidades tecnológicas emergentes e sob uma postura filosófica para a qualidade, objetivando a entrega de valor ao cliente. (NETTO, 2006, p. 27)

Outra conceituação de Gestão por Processos é apresentada como:

Enfoque administrativo aplicado por uma Organização que busca a otimização e
melhoria da cadeia de processos, desenvolvida para atender necessidades e
expectativas das partes interessadas, assegurando o melhor desempenho possível do
sistema integrado a partir da mínima utilização de recursos e do máximo índice de
acerto. (UNICAMP, 2003 apud BARBARÁ, 2006 p. 139)

Uma definição de natureza mais operacional e simples, proposta por Barbará (2006), para o termo é apresentado como: "Modelo de Gestão Organizacional orientado para gerir a organização com foco nos processos”.

Para a gestão da organização, com base na Gestão por Processos, torne-se necessário investigar entre outras as seguintes variáveis (BARBARÁ, 2006):

a. Para que a Organização Existe?

b. Quais são os processos críticos de negócio?

c. Quais são os recursos críticos para gerar os produtos que os clientes desejam adquirir?

d. O que de essencial a organização oferece para os clientes?

e. Como gerenciar o fluxo de informação, trabalho ou atividades e produtos, visando satisfazer os clientes? 


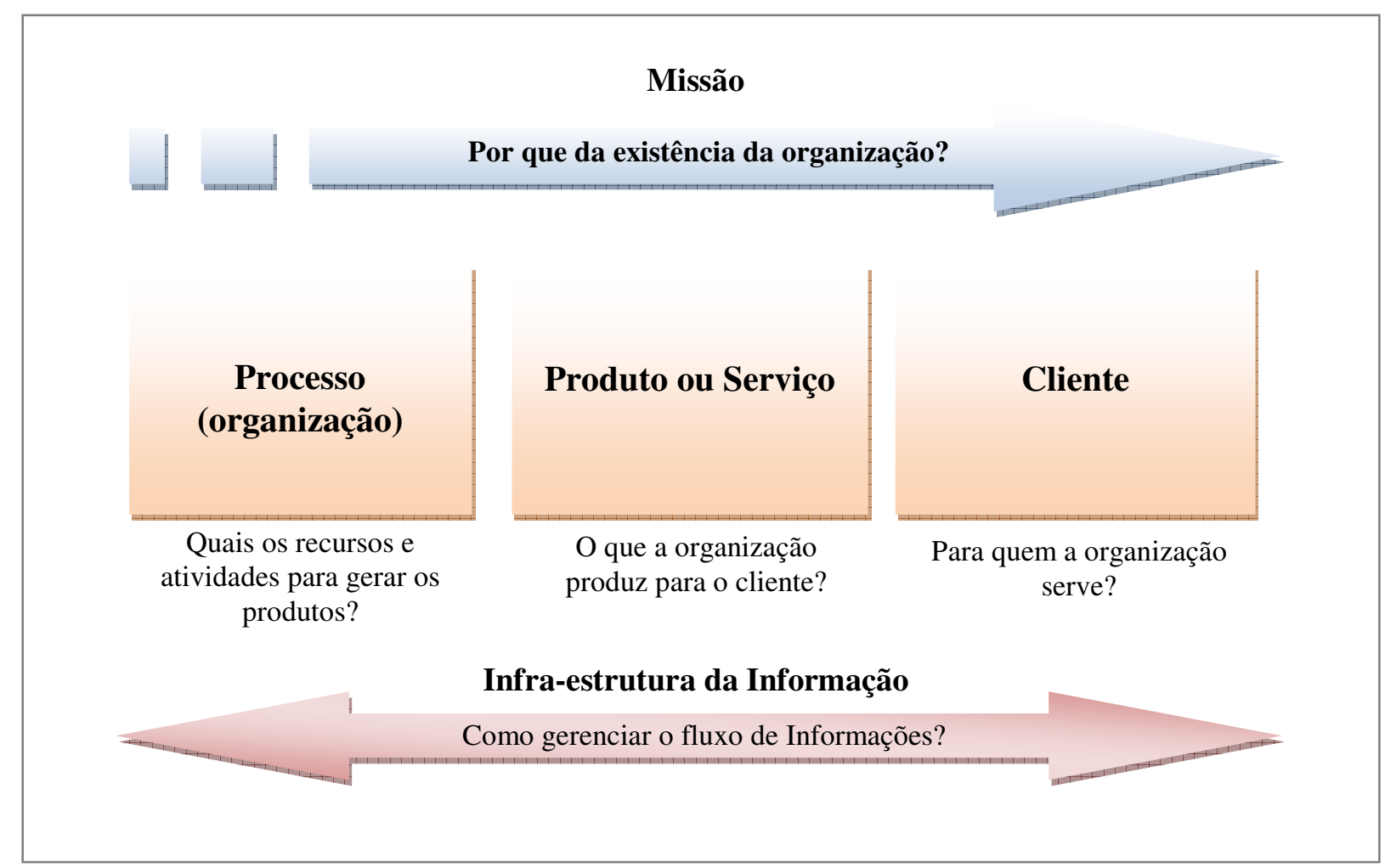

Fonte: (DoD, Framework for MPI, 1994, in Takashina, 2001 - Adptado, apud BARBARÁ, 2006)

Figura 2.1: Modelo de Gestão de Processos

Quanto aos objetivos da gestão por processos, podem-se enumerar, segundo Netto (2006):

a. Aumentar o valor do produto/serviço na percepção do cliente;

b. Aumentar a competitividade, deslocando a concorrência via formas e condições inovadoras de negócios;

c. Atuar segundo a(s) estratégia(s) competitiva(s) considerada(s) mai(s) relevante(s): custos, qualidade, confiabilidade de entregas, velocidade de fluxo, flexibilidade e/ou outras que agreguem valor ao cliente;

d. Aumentar a produtividade, com eficiência e eficácia;

e. Simplificar processos, condensando e/ou eliminando atividades que não acrescentem valor ao cliente.

Alguns importantes princípios sobre a gestão de processos, segundo Netto (2006), são:

a. Organizar em função das saídas, não das tarefas; 
b. Deixar aqueles que usam as saídas do processo executarem o processo;

c. Embutir o trabalho de processamento da informação no trabalho que produz a informação;

d. Tratar recursos dispersos geograficamente como se eles estivessem centralizados;

e. Ligar atividades paralelas, em vez de integrar seus resultados;

f. Colocar o ponto de decisão onde o trabalho é realizado e embutir controle no processo;

g. Obter a informação uma única vez, na fonte;

h. Tomar um enfoque sistêmico dos processos;

i. Criar responsáveis dos processos.

Segundo Gonçalves (2006b), a gestão por processos contemporânea é fundamentada em uma estrutura matricial, onde equipes multifuncionais são responsáveis por cada processo como um todo. Essas equipes têm a responsabilidade e autonomia necessária não só para execução do processo como também para identificar e promover melhorias no desenho do processo. Essas equipes são gerenciadas pelo dono do processo, responsável por assegurar que as saídas do processo sejam adequadas às metas definidas.

\subsection{Gestão de Processos}

Podemos definir a Gestão de Processos como o conjunto de conceitos e práticas direcionados para melhor organizar e gerir os processos de negócios de uma organização. (DAVENPORT 1995, apud GROVER e KETTINGER, 2000).

Segundo Grover e Kettinger (2000), a gestão de processos combina abordagens metodológicas desde gestão de recursos humanos até melhoria dos resultados de mudança nos processos organizacionais. Diferentes métodos, tipicamente adaptados da Engenharia Industrial (ou de produção), Qualidade Total e práticas de Sistemas de Informação têm sido usados na gestão de processos (KETTINGER, 1995 apud GROVER e KETTINGER, 2000).

Grover e Kettinger (2000) definem que gestão de processos é um programa que envolve a formalização ou institucionalização do planejamento, estruturação e avaliação dos processos, esta que pode ser de forma radical (reengenharia) ou de forma incremental 
(melhoria contínua). Aborda ainda que as empresas que se engajarem na gestão de processos devem aplicar múltiplos métodos para coletar informações, redesenhar e acessar seus processos.

Segundo Paim (2002), as organizações buscam os seguintes resultados a partir da aplicação da Gestão de Processos:

a. Uniformização dos entendimentos quanto a forma de trabalho, por meio do uso de modelos para a construção de uma visão homogênea do negócio;

b. Melhoria do fluxo de informação por permitir, com uso da modelagem de processos, a identificação e conseqüente otimização do fluxo de informação;

c. Padronização dos processos, uma vez que a descrição dos processos permite que os mesmos sejam padronizados em função da definição de um referencial;

d. Melhoria da gestão organizacional, o melhor conhecimento dos processos, associados aos indicadores, possibilita o aprimoramento da gestão organizacional;

e. Aumento da conceituação organizacional sobre processos.

f. Redução de tempo e custos dos processos. Este resultado, com enfoque econômico-financeiro sem dúvida o mais procurado pela Gestão de Processos.

\subsection{Conceituação sobre Processos}

A conceituação de processos torna-se importante para este trabalho por conta da falta da consolidação desse conceito dentro das organizações. Por possuírem diversas influências de várias escolas da administração, os processos podem ser vistos sob diferentes enfoques.

Segundo Hammer e Champy (1994), o processo é um grupo de atividades realizadas numa seqüência lógica com o objetivo de produzir um bem ou serviço que tem valor para um grupo específico de clientes.

Para Gonçalves (2000a), um processo é qualquer atividade ou conjunto de atividades que toma um input (entradas), adiciona valor a ele e fornece um output (saídas) a um cliente específico. 


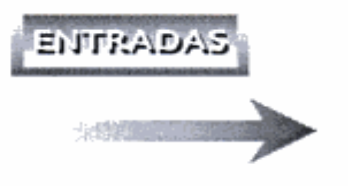

- MATERIAIS

- SERVIÇOS

- INFORMAÇÕES

\section{SAIDAIS}

PROSESSO

(TRANSFORMAÇOES)

- SERVICOS

- INFORMAÇŌES

Fonte: MARANHÃO e MACIEIRA, 2004, p. 12.

Figura 2.2: Modelo de um Processo Genérico

Processo, na visão de Barbará (2006), é o conjunto de ações ordenadas e integradas para um fim produtivo específico, ao final do qual serão gerados produtos e/ou serviços e/ou informações. Processos são resultados dos sistemas de ação, representados por fluxos de atividades ou eventos.

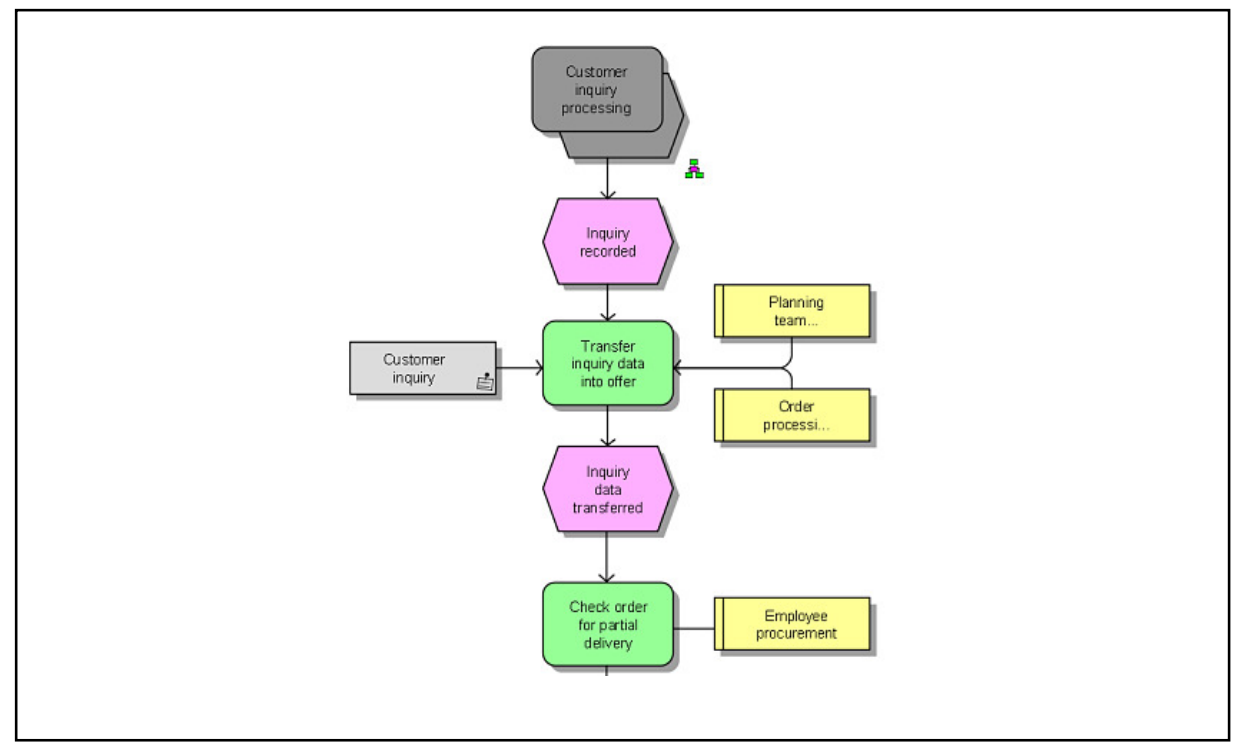

Fonte: www.ids-scheer.com.br

Figura 2.3: Exemplo de um Processo representado através de um Fluxograma.

Dentro das organizações, existem diversos processos que, segundo Cruz (2003), são classificados em dois tipos: (a) primários: processos que estão diretamente ligados à produção do produto que a organização tem por objetivo disponibilizar para seus clientes; (b) secundários: são os processos, também chamados de processos de suporte, que suportam tanto os processos primários quanto os secundários, dando-lhes condições para que possam existir.

Já o Guia D Simplificação do GESPÚBLICA, elaborado pelo Ministério do Planejamento, Orçamento e Gestão (2006) classifica os processos também em dois grupos. 
Esta classificação é semelhante à apresentada por Cruz (2003), porém possui enfoque nas organizações públicas e possui denominações diferentes. Os dois grupos de processos são: (a) finalísticos: diretamente relacionados à essência do funcionamento/missão da organização e/ou diretamente envolvidos no atendimento às necessidades dos seus cidadãos/usuários; (b) de apoio: são essenciais para a gestão efetiva da organização, garantindo o suporte adequado aos processos finalísticos, ou seja, à atividade-fim da organização, tais como: gestão de pessoas, gestão de material, planejamento e acompanhamento das ações institucionais, desenvolvimento de tecnologia da informação e execução orçamentário-financeira.

A partir do momento que se é entendido a natureza dos processos e sua importância para a organização, seja o processo primário ou secundário, surge a necessidade do seu gerenciamento a fim de melhorá-los. Para isso, é necessário tanto uma análise como uma avaliação critica das práticas da organização a respeito dos seus processos. Para tal, a modelagem de processo é a ferramenta apropriada para sua análise, tendo em vista que ela possui uma visualização completa e conseqüente compreensão das atividades executadas dentro de um processo, assim como a inter-relação entre elas. (CORREIA; LEAL; ALMEIDA, 2002).

\subsection{Modelagem de Processos}

A modelagem de processos consiste em construir uma representação de um processo real refletindo suas características com o nível ideal de detalhamento desejado (TORRES, 2002). Ela permite que sejam conhecidas com detalhes e profundidade todas as operações que ocorrem durante a fabricação de um produto ou a produção de um serviço, ou seja, as operações de um processo (ROTONDARO, 2006). Segundo Paim (2002) a modelagem de processos é um instrumento central para a aplicação da Gestão de Processos.

A modelagem de processos também é vista como uma ferramenta gerencial analítica e de comunicação que têm a intenção de ajudar a melhorar os processos existentes ou de implantar uma nova estrutura voltada para processos. Por ser uma ferramenta que possibilita o melhor entendimento dos processos atuais, a sua análise estruturada permite a redução de custos no desenvolvimento de produtos e serviços, a redução nas falhas de integração entre sistemas e eliminar ou simplificar processos quando necessário (HUNT, 1996 apud VILLELA, 2000). 


\subsubsection{Objetivos , Motivações e Benefícios da Modelagem de Processos}

Segundo Vernadat (1996 apud PAIM 2002) a modelagem de processos é essencial para que ocorram integração e coordenação nas organizações. Sendo assim, segundo PAIM (2002) a modelagem tem os seguintes objetivos:

a. Um melhor entendimento e representação uniforme da empresa;

b. Suportar o projeto de novas partes da organização;

c. Um modelo utilizado para controlar e monitorar as operações da empresa.

Quanto às motivações para a modelagem de processos, Vernadat (1996 apud PAIM 2002) apresenta os seguintes pontos:

a. Gestão de sistemas complexos: Esta motivação está relacionada em analisar alguns aspectos da organização, como o aspecto econômico, o organizacional, o layout entre outros, para assim realizar melhores decisões sobre as operações e organização da empresa.

b. Melhor gestão de todos os tipos de processos: Possui o propósito de representar ou entender de uma melhor forma como a organização funciona, ou alguma parte dela;

c. Explicitação do conhecimento e know how organizacional: Tem o propósito de usar e explicitar os conhecimentos adquiridos e as experiências para usos futuros; racionalizar e assegurar o fluxo de informações dentro da organização.

d. Reengenharia de Processos: Consiste em projetar ou re-projetar e especificar uma parte da organização, podendo ser no aspecto funcional, comportamental, informacional, organizacional ou estrutural;

e. Integração empresarial: Propósito de controlar, coordenar ou monitorar algumas partes da organização, isto é, monitorar processos.

Segundo o autor, os benefícios gerados pela modelagem de processos estão relacionados à construção de cultura e de compartilhamento de uma visão comum para a organização via uma mesma linguagem; utilização e explicitação de conhecimento e experiência sobre a organização para construção de uma memória própria, transformando-se em um ativo da organização; e suporte a tomada de decisão considerando a melhoria e controle organizacional. 


\subsubsection{Princípios da Modelagem de Processos}

Segundo Paim (2002) os princípios da modelagem são essenciais para um bom exercício das ações ligadas à criação de modelos. Os princípios apresentados são:

a. Aderência: norteia o entendimento do quão perto o modelo está da estrutura e funcionamento da realidade modelada. Técnicas de levantamento e validação dos modelos de processos são aplicadas para aumentar a aderência e compatibilizar as diferentes percepções acerca de como o processo realmente é;

b. Relevância ou suficiência: cada objeto representado em um dado modelo deve ter um propósito e, neste sentido, um dado modelo não deve conter mais informações do que o necessário. Destaca-se que a definição do que é ou não relevante deve ser cautelosa;

c. Custo/benefício: para a aplicação deste princípio deve ser analisada a quantidade de trabalho necessária para criar o modelo versus utilidade do modelo versus quanto tempo o modelo será usado;

d. Clareza: Está relacionado à capacidade do modelo adotado ser entendido e usado pelos usuários.

e. Comparabilidade: possibilidade de comparação de diferentes processos, logo, apresenta como necessários a aplicação do mesmo método para diferentes processos.

f. Estruturação sistemática: este princípio está ligado capacidade de integrar modelos representando diversos aspectos da realidade e, neste sentido, a capacidade destes modelos de se estruturarem metodologicamente.

\subsubsection{Métodos de Modelagem de Processos}

Não é objetivo deste projeto aprofundar na discrição dos métodos e técnicas existentes que suportam a ação de Modelagem de Processos, tendo em vista que são inúmeros os métodos para esse fim (PAIM, 2002). Cabe ser feito uma abordagem superficial sobre o assunto apresentando características semelhantes a todos os métodos. 
Os métodos para Modelagem de Processos, de uma forma geral, têm o objetivo de prover uma linguagem comum e estruturada a esta ação (PAIM, 2002). Existem diversas técnicas disponíveis de representação usadas para construir modelos de processo que auxiliam na elaboração de diferentes tipos de fluxos (CORREIA, LEAL e ALMEIDA, 2002). Independentemente da técnica utilizada, a modelagem baseia-se, normalmente, nas seguintes etapas (BIAZZO, 2000 apud CORREIA, LEAL e ALMEIDA, 2002): (a) Definição das fronteiras e dos clientes do processo; dos principais inputs e outputs; e dos atores envolvidos no fluxo de trabalho; (b) Entrevistas com os responsáveis pelas várias atividades dentro do processo por um entrevistador assessorado por um modelador; e estudo dos documentos disponíveis; (c) Criação do modelo com base na informação adquirida; e revisão passo a passo do modelo.

\subsubsection{Níveis de Detalhamento na Modelagem de Processos}

A prática de modelagem de processos tem mostrado a existência de uma ampla dificuldade para a modelagem uniforme, esta sendo influenciada por dois fatores: nível de detalhamento e complexidade do modelo de representação (PAIM, 2002). Sendo assim, tornase importante uma análise dos aspectos que influenciam a definição e uniformização do nível de detalhamento em uma modelagem sendo este o objeto de estudo da presente monografia.

Segundo Paim (2002), o fator complexidade do modelo de representação é mais fácil de controlar do que o outro fator tendo em vista que, primeiro, está relacionado com a quantidade de tipos de objetos utilizados no modelo, este determinado em função do método escolhido; segundo, está relacionado à própria característica do processo, na qual figuram atividades que para serem executadas dependem muito dos recursos como, por exemplo: diferentes executores, muitos sistemas de informação, diferentes documentos, entre outros.

Outra abordagem para complexidade de processos é apresentada por Cruz (2003). Segundo o autor, a descoberta da complexidade do processo só será realizada ao inicio da interação com o processo em questão. Aborda sobre a visão de alguns autores definirem a complexidade de um processo pela quantidade de atividades que o processo tem, e sobre a visão de outros autores definirem a complexidade do processo pela quantidade de entradas ou pela quantidade de produtos que o processo produz. Segundo Cruz (2003), quando o processo é considerado complexo por conta do seu número de atividade, esse deve ser subdivido em subprocessos, facilitando assim sua compreensão e análise. Processos que possuem grande 
abrangência em termos de estrutura organizacional também devem ser subdivididos para o aumento dos pontos de controle.

Ao se tratar do nível de detalhamento da modelagem é expressivamente mais difícil de definir e de uniformizar. Mesmo quando se tem critérios definidos para orientar os níveis de detalhamento, a influência do entrevistado, do entrevistador e do modelador é amplamente impactante no grau de agregação do modelo (PAIM, 2002).

As influências do entrevistado, este que deve estar envolvido com a execução do processo, no nível de detalhamento pode ser de forma deliberada ou inconscientemente feita. As razões para tal variam consideravelmente. Há a possibilidade, por exemplo, do interlocutor ter experiência no processo e realizar uma descrição conceitual pouco detalhada ou, inversamente, ser pouco experiente e descrever o processo de forma mais profunda. $\mathrm{O}$ entrevistado pode, também, induzir conscientemente o nível de detalhamento para um patamar mais alto, aumentando, assim, suas responsabilidades no processo, ou para patamar mais baixo de detalhamento, caso tenha o objetivo inverso (PAIM, 2002).

Do outro lado, o entrevistador e o modelador, em função da suas experiências, também, têm forte influência no nível de detalhamento. Caso sejam mais experientes, poderão fazer uma descrição mais uniforme norteando a descrição do entrevistado. Cabe, também, ao entrevistador e ao modelador o papel de uniformizar a complexidade dos modelos de representação, estes devem ser definidos em função dos objetivos da modelagem e dos métodos aplicados (PAIM, 2002).

Para a definição e uniformização do nível de detalhamento, um ponto que deve ser levado em consideração é o grau de agregação que a descrição do processo deve possuir (CAMEIRA, 1998 apud PAIM, 2002). Segundo o autor, não há uma regra exata. O recomendado a se fazer é listar uma série de questões balizadoras que facilitam a identificação de até onde desagregar, sempre permeado pelo bom senso e pela experiência de quem conduz a modelagem. Os seguintes pontos balizadores devem ser levados em consideração segundo o mesmo autor:

a. O processo deve descrever claramente o fluxo de informação e os materiais e documentos associados. Um processo que não permite esse claro entendimento é falho em seu grau de agregação. Sendo assim, é necessário um maior detalhamento. Inversamente, se existe atividades que em nada somam a esse 
entendimento, com grau de desagregação elevado, minucioso, passa de uma descrição do processo e passa a se descrever um procedimento;

b. Se o objetivo é o entendimento rápido e global de como são os macroprocessos de uma organização, não se deve desagregar demais um processo. Contudo, se é desejado intervir nesse fluxo transversal de informação e tornar visível a todos os integrantes sobre o que cada um é responsável, um detalhamento macro é insuficiente. O mesmo acontece se for considerado, dependendo das características do negócio, que alguns problemas ou ganhos operacionais estão travados nos processos operacionais e estes não aparecem na modelagem.

Já Cruz (2003), aborda que a documentação de qualquer processo pode ser feita em três níveis distintos, mas complementares. Segundo o autor, o motivo para o qual se está realizando o trabalho de levantamento e documentação de processos vai ditar o nível de profundidade requerida na documentação. São esses os níveis:

1. Nível Básico: Este é o primeiro nível de detalhamento da documentação. Serve especificamente para a possibilidade de se conhecer o processo por meio do levantamento de suas atividades, papéis funcionais e padrões de medição de controle e desempenho. Esse nível tem como alguns dos objetivos: fazer com que a organização conheça a si mesma; organizar e gerenciar processos; controlar atividades.

2. Nível Intermediário: Este nível está intimamente ligado à adoção de normas de gestão, como ISO 9000, 1400, entre outros. A fim de obter essas certificações, uma organização necessita descer a um nível maior de detalhamento para refletir exatamente como um bem ou serviço é produzido, de acordo com o exigido por essas normas.

3. Nível Avançado: Este nível está relacionado ao nível exigido para a implantação de um software com tecnologia inteligente, como Workflow, por exemplo, para a automação de um determinado processo.

Paim (2002) propõe os seguintes critérios para uniformizar os níveis de detalhamento após uma análise de diferentes autores e por análise de casos: (a) Deve haver um referencial que explicite os níveis de detalhamento. Este referencial definirá, a partir dos objetivos do projeto, quantos níveis serão utilizados e deverá possuir uma descrição e exemplo de cada nível desejado; (b) Deve haver uma ação de comparação dos modelos gerados com o objetivo 
de uniformizar o nível de detalhamento; (c) Deve, idealmente, haver um tipo de modelo por nível de detalhamento. Este critério não é fundamental, mas facilita a uniformização; (d) Em cada nível de detalhamento, diferentes objetos devem ser utilizados, mas deve haver um desdobramento e consistência entre os mesmos.

\subsection{Falhas da aplicação da Gestão de Processos}

Na prestação de serviços de consultoria de modelagem de processos para organizações demandantes podem ocorrer diversas falhas que impactam nos resultados dos projetos. Se tratando de serviços, por possuírem a características de serem únicos, os motivos de falhas podem ser totalmente diferentes e suas ocorrências também. No entanto, Paim (2002) observa algumas causas de falhas que apresenta grande ocorrência de acontecimentos. São elas:

1. Falhas relacionadas à necessidade de conhecimentos específicos, a gestão da mudança e a gestão de projeto (integração do projeto e comunicação).

2. Falta de apoio da alta gestão, a falta de comunicação no projeto e falta de conhecimento e gestão da Tecnologia da Informação;

3. Mal atendida necessidade de tecnologias para sustentar às infra-estruturas sociais, da qualidade, de suporte, do negócio, de informação, técnicas e para inovação e assim reduzir riscos, acelerar a velocidade de inovação e melhorar os resultados de projetos;

4. Falta de recursos humanos; gestão do projeto; gestão da mudança; planejamento tático; delineamento do processo; planejamento estratégico; tempo disponível; e competência tecnológica;

5. Falhas na modelagem e integração empresarial como o alto custo, tamanho e duração do projeto; complexidade; e suporte da gestão.

\subsection{Conceituação de Serviços}

Como o objeto de estudo dessa monografia está relacionado à prestação de serviços por parte de consultorias especializadas em modelagem de processos para organizações demandantes, torna-se necessário uma conceituação sobre a natureza dos serviços a fim de que se faça uma abordagem conceitual mais abrangente do objeto. 
As definições contemporâneas sobre serviços estão relacionadas, segundo Meirelles (2006), em duas abordagens. A primeira possui análise centrada nas características de oferta, ou seja, nas características de produção de um serviço. A outra abordagem está centrada nas características de consumo, relacionadas às funções desempenhadas pelos serviços e o público a que se destinam.

A análise focada na oferta define três características que distinguem os serviços das demais atividades econômicas: (a) fluxo: reflete fundamentalmente as propriedades de simultaneidade e de continuidade do processo de prestação do serviço; (b) variedade: se refere à diversidade de técnicas produtivas e às diferenças no tamanho e na margem de lucro das empresas prestadoras de serviço; (c) o uso intensivo de recursos humanos: reflete o fato de que, apesar da crescente incorporação do progresso técnico, através de máquinas e equipamentos, os recursos humanos representam o fator produtivo predominante no processo de prestação de serviço, principalmente porque serviço é uma atividade profundamente interativa (MEIRELLES, 2006).

As abordagens centradas nas características de demanda buscam, por sua vez, analisar os serviços a partir do seu uso, a partir da função desempenhada e do tipo de consumidor. Neste sentido, a classificação destas atividades se dá em duas categorias básicas: (a) serviços intermediários: também denominados de serviços produtivos, são orientados para o desenvolvimento das atividades produtivas da indústria e das empresas; (b) serviços finais: também denominados de serviços de consumo, são orientados para o desenvolvimento das atividades para o uso individual (serviços domésticos, lazer, entretenimento) e coletivo (segurança, saúde, educação) (MEIRELLES, 2006).

Meirelles (2006) apresenta uma nova proposta de abordagem separando a prestação de serviço em três níveis, distinguíveis de acordo com o processo econômico no qual o serviço se insere: nos processos de trabalho puro (no qual o serviço de consultoria é enquadrado), nos processos de transformação e produção ou nos processos de troca e circulação, conforme quadro abaixo: 


\begin{tabular}{|c|c|c|}
\hline $\begin{array}{l}\text { Processo } \\
\text { Econômico }\end{array}$ & Tipo de serviço & Exemplos \\
\hline $\begin{array}{l}\text { Processo de } \\
\text { trabalho puro }\end{array}$ & $\begin{array}{l}\text { Serviço puro } \\
\text { Consiste em realizar um trabalho único } \\
\text { e exclusivo. O resultado do processo de } \\
\text { trabalho é o próprio trabalho, não há } \\
\text { necessariamente um produto resultante. }\end{array}$ & $\begin{array}{l}\text { Serviços domésticos; Serviços } \\
\text { de entretenimento e lazer; } \\
\text { Serviços de consultoria; } \\
\text { Serviços de assistência técnica; } \\
\text { Serviços de pesquisa e } \\
\text { desenvolvimento de produtos; } \\
\text { Serviços de saúde e educaçāo; } \\
\text { Serviços governamentais de } \\
\text { defesa e segurança, etc. }\end{array}$ \\
\hline $\begin{array}{l}\text { Processo de } \\
\text { transformaçāo }\end{array}$ & $\begin{array}{l}\text { Serviço de transformaçāo } \\
\text { Consiste em realizar o trabalho necessário } \\
\text { à transformaçāo de insumos e } \\
\text { matérias-primas em novos produtos. }\end{array}$ & $\begin{array}{l}\text { Serviços de alimentação; } \\
\text { Serviços decorrentes da } \\
\text { terceirização de etapas do } \\
\text { processo de transformaçāo. }\end{array}$ \\
\hline $\begin{array}{l}\text { Processo de troca } \\
\text { e circulação }\end{array}$ & $\begin{array}{l}\text { Serviço de troca e circulação } \\
\text { Consiste em realizar o trabalho de troca } \\
\text { e circulaçāo, seja de pessoas, bens } \\
\text { (tangiveis ou intangiveis), moeda, etc. }\end{array}$ & $\begin{array}{l}\text { Serviços Bancários; } \\
\text { Serviços Comerciais; } \\
\text { Serviços de armazenamento } \\
\text { e transporte; Serviços de } \\
\text { comunicação; Serviços } \\
\text { de distribuiçāo de energia } \\
\text { elétrica, água, etc. }\end{array}$ \\
\hline
\end{tabular}

Fonte: MEIRELLES, 2006.

Figura 2.4: Propostas de Classificação das Atividades de Serviço

Quanto às principais características dos serviços, como podemos ver na tabela a baixo, Miles (1993, apud MEIRELLES, 2006) as apresenta em quatro principais grupos de acordo com sua natureza.

\begin{tabular}{|c|c|}
\hline Processo de Produção & $\begin{array}{l}\text { - Pesados investimentos em prédios e construçōes: necessidade de } \\
\text { espaço fisico para a integraçāo produtor-usuário. } \\
\text {-Alguns sāo intensivos em māo-de-obra especializada e altamente } \\
\text { qualificada, outros nāo. } \\
\text {-A organizaçāo do processo de trabalho é sempre problemática porque } \\
\text { é difícil controlar e administrar o processo nos mínimos detalhes. }\end{array}$ \\
\hline Produto & $\begin{array}{l}\text { - Intangivel e intensivo em informaçāo. } \\
\text { - Inestocável e de difícil transporte. Processo e produto sāo } \\
\text { praticamente indistinguiveis. } \\
\text { - Quase sempre customizado, atendendo especificidades do mercado } \\
\text { consumidor. }\end{array}$ \\
\hline Consumo & $\begin{array}{l}\text {-A produção e o consumo sāo instantâneos no tempo e no espaço. } \\
\text { ·A produçāo depende de especificaçōes do consumidor quanto a } \\
\text { design e ao próprio processo de produção. }\end{array}$ \\
\hline Mercado & $\begin{array}{l}\text {-A organização do mercado varia, desde serviços públicos administrados } \\
\text { pelo governo até serviços privados operados em pequena escala por } \\
\text { empresas familiares. } \\
\text { - Via de regra há dispositivos e mecanismos institucionais de regulaçāo } \\
\text { do mercado, com o objetivo de proteger o consumidor e orientá-lo nas } \\
\text { suas decisōes de consumo, tendo em vista a dificuldade de } \\
\text { demonstração dos produtos antecipadamente. }\end{array}$ \\
\hline
\end{tabular}

Fonte: MILES 1993, apud MEIRELLES, 2006.

Figura 2.5: Características e atributos específicos dos serviços 
Em síntese, os serviços de consultoria estão enquadrados segundo Meirelles (2006) no tipo de Serviço Puro, aquele que é único e exclusivo. Estão relacionados, na abordagem por demanda, como serviços do tipo intermediários, ou seja, orientados para o desenvolvimento das atividades produtivas da indústria e das empresas. Possuem como características marcantes a partir da relação apresentadas por Miles (1993, apud MEIRELLES, 2006): (a) processos de trabalho problemático por conta da dificuldade de administrar os processos nos mínimos detalhes; (b) produtos sempre customizados, atendendo, necessariamente as especificações do consumidor; (c) necessidade de mão de obra especializada e altamente qualificada para a execução do serviço; (d) forte dificuldade de se demonstrar antecipadamente os produtos que serão entregues. 


\section{MÉTODOS E TÉCNICAS DE PESQUISA}

A delimitação dos métodos e técnicas a serem utilizados em uma pesquisa, independente de sua natureza, é essencial por estar ligado diretamente com a eficácia de sua realização, tomando como base que método é uma seqüência de procedimentos mais ou menos padronizada (TOMANIK, 1994).

Assim sendo, esse item do projeto tem como intuito apresentar os métodos e técnicas utilizadas para a execução deste projeto

\subsection{Delineamento da pesquisa}

O presente projeto foi realizado em quatro diferentes fases:

1. Delimitação do objeto de estudo: nesta etapa, foi levantada a existência da problemática e por conseqüências os objetivos a serem atingidos com a realização deste trabalho. Nesta etapa também foi avaliado a importância e viabilidade de sua realização.

2. Análise do referencial teórico: por se tratar de uma etapa crucial para o projeto, foi feito um levantamento das literaturas afins do tema do projeto com intuito de se criar um conhecimento necessário para a realização das etapas seguintes.

3. Definição do estudo de caso: nesta etapa foi selecionado um estudo de caso que possuía as características necessárias para se enquadrar como objeto de estudo deste trabalho.

4. Coleta e Análise de Dados: Nessa etapa foram feitas as entrevistas com os envolvidos a fim de se coletar os dados para sua posterior análise.

Como já citado, o tipo de pesquisa definido para esse trabalho foi o Estudo de Caso, que segundo Roesch (2007), é uma estratégia de pesquisa que busca examinar um fenômeno atual dentro de seu contexto específico. O método de pesquisa utilizado foi o de Pesquisa Qualitativa, método esse que possui a preocupação com o aprofundamento da compreensão de um grupo social, como por exemplo, uma organização (GOLDENBERG, 1997). 


\subsection{Caracterização do Estudo de Caso}

O estudo de caso escolhido para esse trabalho foi o projeto de Modelagem de Processos realizado na Furnas Centrais Elétricas por uma consultoria especializada. Segundo o site da própria empresa, a Furnas é descrita como:

Uma empresa da administração indireta do Governo Federal, vinculada ao Ministério de Minas e Energia e controlada pela Eletrobrás. Sua missão é atuar como empresa do ciclo da energia elétrica, ofertando produtos a preços razoáveis e serviços adequados para melhorar a condição humana. A visão de FURNAS é ser empresa de excelência no ciclo de energia elétrica contribuindo para o bem-estar da sociedade, o desenvolvimento tecnológico do país e a conservação do meio ambiente.

O projeto de consultoria em questão foi realizado para o mapeamento e modelagem dos Processos do departamento de Engenharia de Telecomunicações de Furnas - DET.E. O projeto foi realizado durante o ano de 2007 e teve uma duração total de 6 (seis) meses sendo executado nas seguintes etapas:

1. Revisão da cadeia de valor do departamento;

2. Identificação das funções críticas, fatores críticos de sucesso; codificação dos conhecimentos críticos; desenho e documentação da situação atual; avaliação dos pontos fracos e elaboração do diagnóstico do processo; ambiente de execução e recursos;

3. Desenho da situação futura (com melhorias);

4. Simulação da situação desejada;

5. Implementação;

6. Avaliação dos resultados.

\subsection{População da pesquisa}

A população escolhida para aplicação da pesquisa foram aquelas pessoas que estiveram envolvidas diretamente no projeto, ou seja, servidores de Furnas e consultores especializados responsáveis por conduzirem o projeto. 


\subsection{Caracterização dos instrumentos de coleta de dados}

O principal instrumento de pesquisa utilizado na pesquisa foi um questionário elaborado para a condução das entrevistas com o qual se pretendia atingir o objetivo de coletar informações sobre o projeto e as percepções dos entrevistados perante o objeto de estudo dessa monografia. Outra fonte de coleta de dados utilizado foi o edital publicado pela FURNAS para a contratação da consultoria especializada. 


\section{ANÁLISE E INTERPRETAÇÃO DOS RESULTADOS}

Como apresentado por Roesch (2007), os resultados da análise devem ser relacionadas com objetivo geral definido, ou seja, nessa fase é que se perseguem os resultados almejados na pesquisa científica. Sendo assim, este capítulo apresenta os principais resultados gerados a partir dos dados coletados nas entrevistas, esta apresentada no capítulo 3, como também pela interpretação do conhecimento obtido no referencial teórico, atingindo, assim, os objetivos desta pesquisa.

\subsection{Principais fatores relacionados ao Gap}

Pretende-se neste item do projeto a extração dos principais pontos abordados no referencial teórico que estão relacionados com o gap de entendimento quanto ao nível ideal de detalhamento na modelagem de processos, objeto de estudo do presente trabalho.

Como foi abordado no referencial teórico, uma das principais falhas da aplicação da Gestão de Processo, segundo Paim (2002), é própria falha na modelagem dos processos, esta podendo ser impactadas por problemas relacionados ao projeto de modelagem, como seu alto custo, tamanho e duração. Uma boa modelagem de processos, afim de que se atinjam seus objetivos, deve refletir as características dos processos com o nível ideal de detalhamento desejado.

O nível ideal de detalhamento desejado está estritamente relacionado com as motivações da organização interessada na modelagem de processos. Dependendo da motivação, como a de redução de falhas na integração de sistemas de informática, os processos devem estar bem detalhados de forma que ofereça informações suficientes para os envolvidos. Em contrapartida, motivações relacionadas à otimização da tomada de decisão operacional não necessitam de um profundo detalhamento, tendo em vista que uma visão macro dos processos é suficiente (PAIM, 2002; CRUZ, 2003).

Com a proliferação no mercado de diversas metodologias, técnicas e ferramentas destinadas à gestão de processos (PAIM, 2002), várias são as formas de se entender a forma ideal do detalhamento, aumentando, assim, o leque de possibilidades para sua definição e sua uniformização. 
Mesmo quando se tem critérios definidos para orientar os níveis de detalhamento, a influência do entrevistado, do entrevistador e do modelador é amplamente impactante na modelagem (PAIM, 2002).

A correlação entre a definição e uniformização do nível de detalhamento e os princípios da modelagem de processos, apresentado por Paim (2002), é fortemente impactante, tendo posto que a falta de atenção a esses princípios impactará na definição do nível de detalhamento, podendo levar a esforços na modelagem não condizentes com as reais necessidades da organização.

A dificuldade de se estabelecer uma regra única para o detalhamento dos processos por parte de uma consultoria se dá pela variedade dos serviços dessa natureza. Por serem de caráter único e exclusivo para cada cliente, devem estar orientados ao atendimento de suas necessidades, sendo estas das mais diversas variações (MEIRELLES, 2006).

A forte dificuldade de se demonstrar antecipadamente os produtos (resultados) que serão entregues em uma prestação de serviços (MEIRELLES, 2006), faz com a definição de uma regra única para o detalhamento dos processos entre consultoria especializada e organização cliente tornar-se mais difícil.

\subsection{O edital de licitação referente à contratação da consultoria especializada}

Para o entendimento do projeto realizado no Departamento de Engenharia de Telecomunicações de Furnas - DET.E, é necessário uma análise do edital de licitação referente a contratação da consultoria especializada para a prestação do serviço em questão. Segundo orientações da lei $\mathrm{n}^{\mathrm{o}}$ 8.666, de 21 de junho de 1993, um edital deve conter em suas especificações um conjunto de elementos necessários e suficientes, com nível de precisão adequado, para caracterizar o serviço objeto da licitação. Sendo assim, o edital, através de suas especificações técnicas, geralmente inseridas no seu Projeto Básico, descreve o formato da prestação de serviço. No caso do Projeto de Mapeamento e Modelagem de Processos do DET.E, as fontes iniciais de informação da consultoria vencedora da licitação para o entendimento do serviço a ser prestado foram as especificações técnicas contidas no edital.

Segundo essas informações, em 2006, o DET.E elaborou seu planejamento estratégico a fim de por em prática ações estratégicas para atingir sua missão e visão. A missão do DET.E é a de "Planejar, projetar, implantar soluções de telecomunicação que atendam as necessidade operativas e corporativas de Furnas e seus clientes, com uso responsável dos recursos 
envolvidos." Sua visão é a de "Ser reconhecido como órgão ágil e inovador, que efetivamente contribui para a competitividade e a imagem de Furnas." Um dos objetivos estratégicos traçados no seu planejamento estratégico estava relacionado a desenvolver iniciativas para a Modelagem e Otimização de todos os processos organizacionais do departamento. Para o cumprimento de tal objetivo estratégico, foi necessária a contratação de uma consultoria especializada para a realização do mapeamento dos processos.

Para o delineamento dos serviços que seriam prestados, as especificações técnicas dos serviços apresentaram as seguintes informações:

a. Principais etapas do projeto, porém essas etapas foram apresentadas apenas em formato macro, não sendo detalhada a composição de cada etapa;

b. Organograma do Departamento, apresentando suas divisões;

c. Representação gráfica da Cadeia de Valor do DET.E;

d. Os macro processos do DET.E e a quantidade de processos em cada macro processo;

e. Quantidade média de 5 a 10 atividades por Processo;

f. O padrão de modelagem de processos a ser utilizado: BPMN;

g. Prazo de Execução: 6 meses.

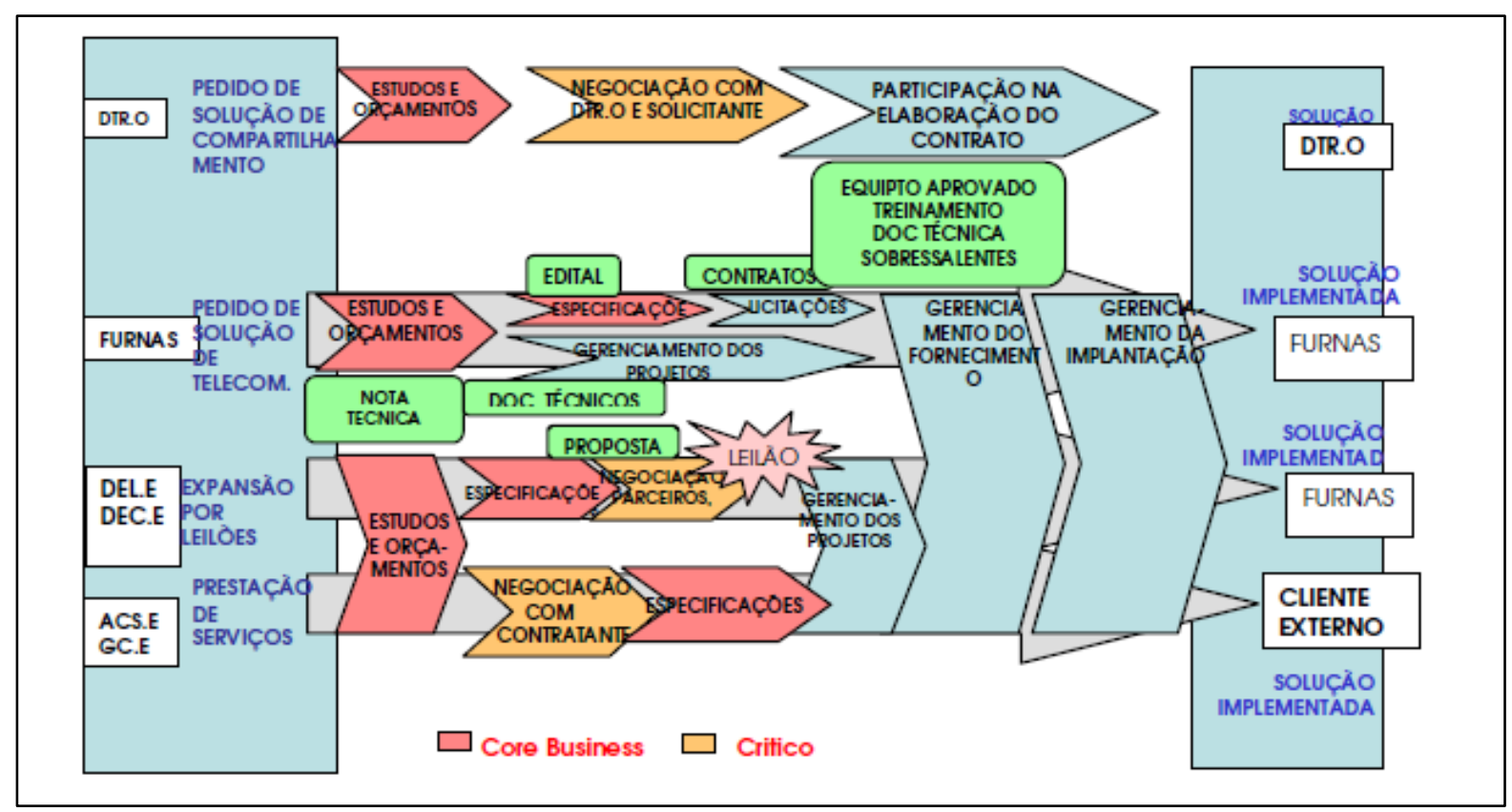

Fonte: FURNAS

Figura 5.1: Cadeia de Valor do DET.E. 
Também são apresentados nas especificações dos serviços os objetivos do Projeto. São dois os objetivos. O primeiro é o de permitir o alcance da visão estratégica do DET.E alinhado aos demais objetivos estratégicos do departamento. O segundo é servir como base para implementação do projeto de "Gestão de Projetos" no departamento.

Por se tratar de uma prestação de serviço cujo seu detalhamento permite uma melhor visualização dos resultados a serem gerados, as especificações técnicas dos serviços contidas no edital não permitem um entendimento concreto das expectativas do DET.E após o encerramento do projeto. Percebe-se a falta de informação sobre:

a. Quais seriam os resultados buscados pelo DET.T a partir da aplicação da Gestão de Processos. Apesar de ser apresentado o objetivo de permitir o alcance da visão do departamento, não se identifica, por exemplo, se o departamento pretende uma padronização dos seus processos, ou se pretende ter um melhor entendimento e representação uniforme de sua estrutura. Esse tipo de direcionamento oferece subsídios para uma definição do nível de detalhamento de um processo;

b. Alguma diretriz referente a até que ponto se tinha o interesse de que um processo fosse representado;

c. Os critérios de aceite dos resultados gerados em cada etapa do projeto. Sem critérios definidos, o atendimento as expectativas podem ser dificultados.

d. Relação esperada de objetos que deveriam ser representados nos fluxogramas dos processos.

\subsection{Análise dos dados coletados nas Entrevistas}

A coleta de dados foi estruturada para o levantamento das percepções sobre o gap por parte da consultoria especializada que realizou o projeto e por parte dos servidores da DET.E que estiveram ligados diretamente com o projeto. As perguntas da entrevista foram feitas com cada grupo separadamente para uma posterior análise dos principais temas abordados na entrevista. As perguntas foram estruturadas de forma descritiva objetivando respostas abrangentes, enriquecendo, desta forma, a obtenção das percepções dos entrevistados. 


\subsubsection{Percepção quanto à existência do gap}

Inicialmente, foi levantado nas entrevistas com os envolvidos no projeto de como foi percebido a existência do gap nos trabalhos desenvolvidos.

Para a consultoria especializada, a percepção quanto à existência do gap ocorreu no momento da análise do edital de licitação responsável pela contratação do serviço. Mesmo sendo citado no edital o número de processos e o número de atividades, essas informações serviram apenas para o dimensionamento do trabalho a ser executado. Porém, esse dimensionamento poderia ser comprometido sem que houvesse um nivelamento no quanto seria necessário detalhar cada processo. Um detalhamento mais profundo acarretaria um maior esforço por parte da consultoria, aumentando custos e prazos de execução do projeto.

Para o DET.E, o gap foi realmente percebido na fase final de leitura e revisão dos fluxogramas resultantes do mapeamento, quando ocorreu a participação de todas as divisões do Departamento e questões referentes ao nível de detalhamento do processos vieram a tona. O gap foi novamente percebido durante a fase de aplicação prática dos novos fluxogramas no dia-dia operacional do Departamento.

\subsubsection{Motivos e Impactos do gap segundo percepção dos entrevistados}

Pretendia-se levantar, segundo as percepções dos entrevistados, quais foram os principais motivos para a ocorrência do gap, como também, quais foram as consequiências decorrentes da existência do gap no andamento e nos resultados do projeto.

Segundo a consultoria especializada, os motivos para a ocorrência do gap estão relacionados à: (a) Dificuldade de definição do nível de detalhamento nas especificações do produto (edital); (b) Desconhecimento da equipe consultora sobre os processos alvo do trabalho, ou seja, os processos da DET.E que seriam mapeados; (c) Desconhecimento da equipe representante do DET.E acerca do nível desejado de detalhamento dos processos.

Com relação aos impactos decorrentes do gap, para a consultoria eles foram: (a) Dificuldade de dimensionamento do tempo necessário à execução do trabalho. (b) Tempo final de duração do projeto; (c) Qualidade percebida pelo cliente; (d) Aumento nos custos do projeto.

Para o Departamento de Engenharia de Telecomunicações de Furnas, os motivos para a ocorrência do gap foram: (a) Falta de atenção parcial dos envolvidos para as especificidades 
dos processos do Departamento; (b) Falta de tempo dos servidores do DET.E para uma maior dedicação ao projeto; (c) Ampla abrangência de interação de alguns processos com outras órgãos de Furnas, dificultando o entendimento de suas especificidades.

Para o DET.E, apesar de considerar o gap não sendo crítico nos resultados do mapeamento, os impactos foram: (a) Não representação fiel da realidade dos processos em alguns casos; (b) Perda de qualidade dos produtos resultantes da aplicação dos processos.

\subsubsection{Motivações para a realização e elaboração do projeto}

Buscou-se nas entrevistas identificar se os motivos da realização do projeto de mapeamento de processos estavam bem claros e bem definidos, como também se estavam bem disseminados entre a consultoria e entre os servidores do DET.E. Além das motivações, foram levantadas as premissas utilizadas pelo Departamento para a elaboração do projeto. Buscou-se, também, identificar se as pessoas envolvidas nessa elaboração possuíam conhecimentos sobre Gestão de Processos.

Por parte da consultoria especializada, as motivações estavam bem claras e bem definidas. Houve um esforço por parte da prestadora de serviço em se conhecer bem essas informações, tendo em vista que as motivações que constavam no edital eram bastante superficiais. As motivações estavam relacionadas à padronização e manualização dos processos do DET.E.

Quanto às premissas, a consultoria não teve conhecimento, porém foi percebido que os servidores da DET.E envolvidos no projeto possuíam conhecimento sobre conceitos de processos como também de ferramentas e técnicas de gestão de processos.

Para o DET.E, os motivos estavam bem claros entre todos os envolvidos no projeto, compreendendo o interesse em elaborar fluxogramas dos processos, até então inexistentes, para o registrar a cultura e a maneira de trabalhar do Departamento, servir de referência para que todos do Departamento entendessem os diversos processos e suas correlações com as outras áreas e servir de referência para o treinamento de novos funcionários. 


\subsubsection{Definição do nível de detalhamento dos processos}

Pretendia-se levantar nas entrevistas, como ocorreu a definição do nível de detalhamento dos processos no projeto buscando-se identificar quais foram os fatores determinantes para a essa definição.

Segundo a consultoria especializada, o nível de detalhamento dos processos foi definido no momento da modelagem de cada processo. Foi definido através da percepção e consenso entre os consultores e os servidores da DET.E responsáveis pelo processo em questão. Para isso, foram levados em considerações o quanto eram significativas as informações advindas das descrições dos processos. Porém, em muitos processos, principalmente aqueles que possuíam apenas um responsável, o nível era definido pelo servidor.

Segundo o DET.E, foi utilizado, no início do projeto, o conceito de "escopo mínimo" para o nível de detalhamento, estipulando, assim, um nível integrado com a cultura do departamento. Com isso, foi imaginado um detalhamento não profundo para os processos no primeiro momento.

\subsubsection{Esclarecimento quanto à metodologia e resultados esperados do projeto}

Buscou-se nas entrevistas levantar se ocorreu, por parte da consultoria especializada, um esforço em se demonstrar a metodologia de Modelagem de Processos que seria utilizada no projeto, como também se houve uma preocupação em se demonstrar quais seriam os resultados alcançados ao seu fim.

Segundo a consultoria especializada, a metodologia a ser utilizada estava bem clara. Por ser um demanda dos servidores da DET.E, ocorreu uma reunião em que os consultores apresentaram quais seriam as ferramentas utilizadas, quais seriam as notações, como seriam as reuniões de modelagem, entre outros. Porém, foi percebido que a metodologia poderia ter sido melhor detalhada no início de projeto. Quanto à demonstração de quais seriam os resultados alcançados no fim do projeto, não ocorreu nenhum esforço. Segundo a empresa contratada, não foi demandando esse tipo de demonstração, ocorrendo apenas um alinhamento conceitual para a execução do serviço. 
Por parte do DET.E, a metodologia a ser utilizada pela consultoria foi constantemente apresentada para os envolvidos do projeto, inclusive com a utilização de comparação vividas pela consultoria especializada em outros clientes.

\subsubsection{Ocorrência de diferentes níveis de detalhamento}

Levantou-se com os entrevistados se houve diferentes níveis de detalhamento para cada processo influenciado por sua complexidade, como também, pelo grau de competência do executor do processo.

Segundo a consultoria, houve diferentes níveis de detalhamento nos processos mapeados do DET.E. Processos que possuíam atividades tecnicamente mais complexas eram mais detalhados, se comparadas a atividade conhecidas por um número maior de pessoas e que possuíam características mais rotineiras. Ao se tratar de processos ligados a atividades fim do departamento, também ocorreu um maior foco e detalhamento. Quanto à diferenciação de nível de detalhamento motivada pelo grau de competência do executor, não foi percebido nenhuma ocorrência, mesmo porque o grau de competência dos executores era similar, diminuindo assim possíveis efeitos decorrentes a essa questão.

Para o DET.E, não ocorreram diferenciação no nível de detalhamento dos processos por conta da sua complexidade e nem por conta do grau de competência do executor do processo. Em linhas gerais, para o departamento, os processos tiveram um nível similar de detalhamento.

\subsection{Causas e Impactos do Gap}

A partir da análise dos dados levantados na entrevista, da análise do edital de contratação do serviço e dos fluxogramas gerados no projeto realizados no DET.E, foi possível chegar aos principais motivos e impactos do gap de entendimento entre consultorias especializadas e organizações clientes quanto ao nível ideal de detalhamento na modelagem de processos, apresentado na seguinte figura: 


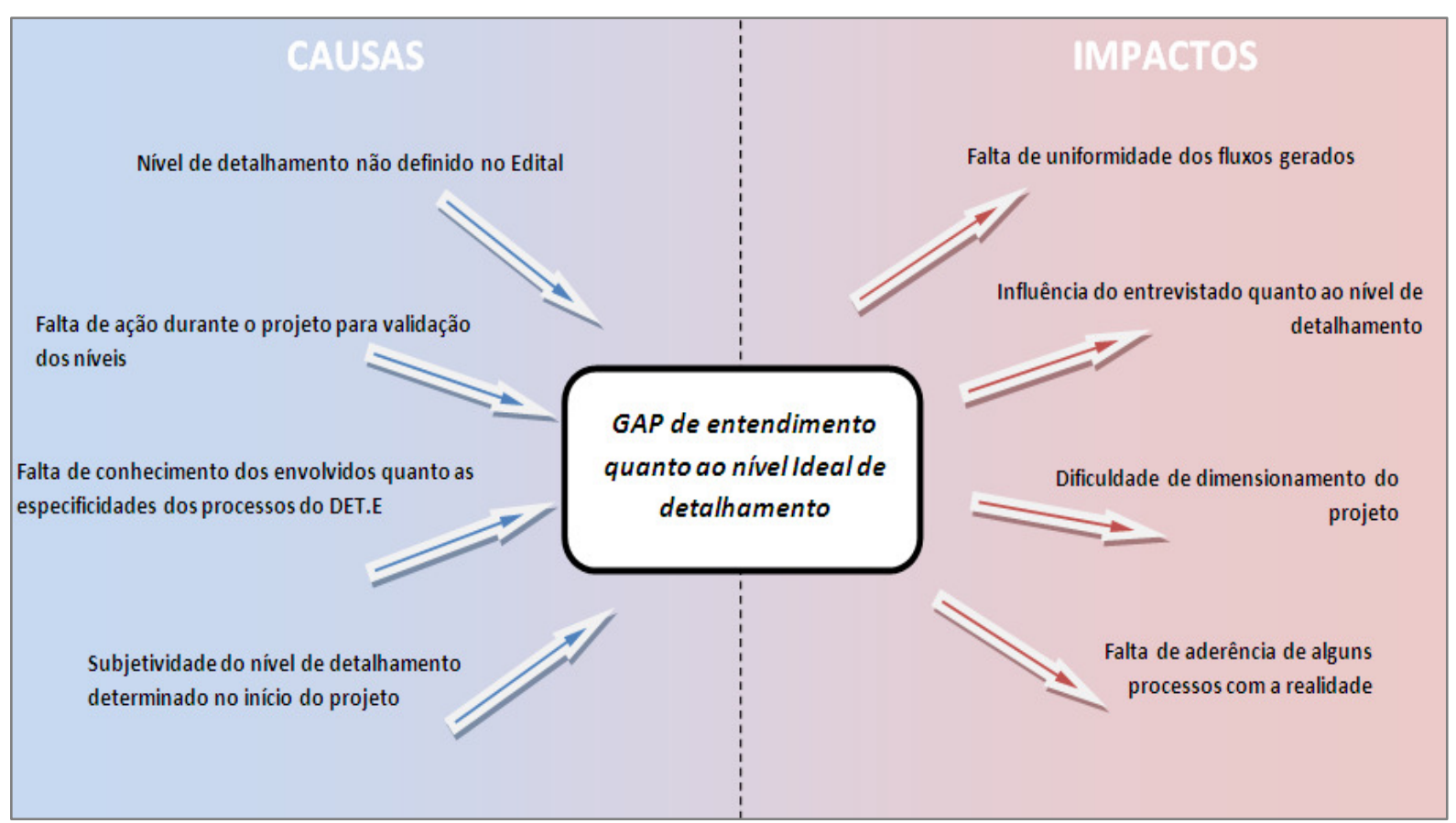

Fonte: Pesquisa realizada pelo autor, 2009.

Figura 5.2: Causas e Impactos do GAP.

Como apresentado na figura 5.2, uma das causas para a ocorrência do GAP se deu por conta da não definição no edital quanto ao nível de detalhamento dos processos no serviço de modelagem. Por se tratar do principal instrumento para a definição do serviço a ser prestado, essa não delimitação gera conseqüências na execução dos trabalhos, dificultando, por exemplo, o dimensionamento do projeto em tempo, custo, riscos, por parte da consultoria especializada.

Outra causa percebida foi a falta de ação durante o projeto para validação dos níveis gerados. Durante as entrevistas, foi levantado que a consultoria especializada realizou, assim que identificou a existência do gap, uma reunião inicial com o DET.E para tratar sobre o assunto. A reunião tinha o objetivo de minimizar as divergências quanto o nível desejado de detalhamento. Porém, apesar da preocupação e do consenso da existência do problema, nenhuma solução concreta ficou configurada e a determinação foi de dar andamento as atividades e que o nível de detalhamento seria coerente a cada processo. No decorrer do projeto, não ocorreu nenhuma validação por parte do Departamento para saber se os processos estavam com o detalhamento coerente. Apenas foi realizado, ao fim do projeto, um reunião com todas as divisões do DET.E para validação dos fluxos, sendo tarde, portanto, para a realização de grandes correções. 
A falta de conhecimento dos envolvidos quanto as especificidades dos processos do DET.E se encontra como uma das causas da ocorrência do gap. A falta de conhecimento dos processos a serem mapeados ocorreu tanto com a consultoria especializada, quanto com o DET.E. Para este, o gargalo de conhecimento estava relacionado com as interações de seus processos com órgãos externos. Esse não conhecimento das especificidades dificulta consideravelmente na definição do nível de detalhamento ideal para os processos. Não se conhecendo a complexidade das atividades do processo, por exemplo, pode se conduzir para um mapeamento superficial, dificultando um novo executor do processo a aplicá-lo com eficiência. Conhecendo-se melhor o processo que vai ser mapeado, aplicar os princípios da Relevância e do Custo Benefício da modelagem de processos torna-se mais eficiente.

A última causa identificada foi à subjetividade do nível de detalhamento determinado no início do projeto. Como foi apresentado, mapear um processo até um nível que se julgue coerente, como foi definido entre a consultoria e o Departamento, tornou-se perigoso, pois o entendimento de coerente pode não ser igual entre os envolvidos. Se o nível de detalhamento fosse determinado por fatores objetivos, sem sombras para interpretações, a definição do detalhamento estaria clara e uniformizada. Nesse contexto, percebeu-se que a definição do nível coerente para cada processo acabou sendo definido unilateralmente pelo DET.E.

No grupo de impactos, o primeiro identificado está relacionado com a falta de uniformidade quanto ao nível de detalhamento dos diversos fluxos gerados pelo mapeamento. Como cada processo teve seu detalhamento determinado separadamente, percebeu-se, conseqüentemente, que os processos tiveram diferentes níveis de detalhamento. A falta de uniformidade dos processos causa a impossibilidade de comparação entre os diversos fluxos, sendo a comparabilidade, segundo Paim (2002), um dos princípios a ser seguido pela modelagem de processos.

O segundo impacto identificado no estudo de caso foi a influência do entrevistado na definição do nível de detalhamento do processo. Durante as entrevistas de levantamento de processos, os entrevistados eram as pessoas responsáveis pela a execução dos processos em questão. Sendo assim, o julgamento de valor do entrevistado para o nível de detalhamento serviu de diretriz para o fluxo daquele processo. Para o entrevistado, realmente o fluxo gerado fornecia as informações necessárias, porém, esse mesmo fluxo pode ser julgado por outro executor como não adequado. Tendo como um dos motivos do projeto possuir fluxogramas para servir de referência para o treinamento de novos funcionários, percebe-se a grande conseqüência negativa desse impacto. 
Outro impacto identificado foi a dificuldade de dimensionamento do projeto por conta da não definição objetiva do nível de detalhamento. Diferentes níveis de modelagem requerem níveis de esforço para execução do mapeamento. Quando se trata de processos com maior detalhamento, por exemplo, o tempo necessário para sua realização aumenta, como também o custo de execução do serviço. Por conseqüência, a não precisão quanto tempo gasto na modelagem gerou dificuldades em acertos de agenda e disponibilidade das pessoas envolvidas.

O último impacto identificado foi a falta de aderência de alguns fluxogramas de processos com a realidade. Esse impacto realmente foi sentido no momento da aplicação no dia a dia do Departamento de alguns fluxogramas que tiveram um menor nível de detalhamento. Por não ter sido mais detalhado, esses fluxogramas não apresentam certas etapas do processo, tornando-os infiéis aos processos, e conseqüentemente, pouco aplicáveis na prática. 


\section{CONSIDERAÇÕES FINAIS}

Cada vez mais, as organizações contemporâneas buscam maior eficiência operacional como forma de se tornarem competitivas. Diante desse contexto, a gestão de processos permite as organizações atuarem de forma ágil, integrada e flexível, adaptando-se ao novo cenário competitivo e dinâmico. Com isso, diversas iniciativas em gestão de processos são realizadas por essas organizações apoiadas, geralmente, por consultorias especializadas. Iniciativas, estas, baseadas sobretudo em Modelagem de Processos, principal ferramenta de suporte a Gestão de Processos.

A boa prática de modelagem de processos deve seguir princípios que estão relacionados à aderência dos fluxos com a realidade, relevância das informações contidas nos modelos, custo beneficio do esforço no detalhamento dos processos e por fim a clareza e comparabilidade dos fluxos. A prática de modelagem de processos tem mostrado a existência de uma ampla dificuldade relacionada à definição do nível ideal de detalhamento de processo. Diversos são os fatores que dificultam tanto as organizações quanto as consultorias especializadas a chegarem nessa definição. Temos como exemplo o gap de entendimento quanto ao que é considerado ideal como detalhamento de processo. O não alinhamento entre as duas partes quanto a esse nível pode ocasionar o não cumprimento das expectativas da organização cliente quanto aos serviços prestados, pois os processos fluxogramados podem omitir informações ou exceder com a quantidade de informações.

Este trabalho buscou identificar, portanto, os impactos causados pelo gap de entendimento entre consultorias especializadas e organizações clientes quanto ao nível ideal de detalhamento na modelagem de processos considerando como estudo de caso o projeto realizado no Departamento de Telecomunicações de Furnas Centrais Elétricas. Os resultados obtidos a partir das pesquisas de dados primários e secundários permitiram a identificação dos impactos, bem como as causas da ocorrência do gap.

Apesar de não ter sido encontrado dados secundários que abordem diretamente o gap, as informações extraídas no referencial teórico permitiram a formação de uma massa de conhecimento crítica para a estruturação dos fatores que estão relacionados com objeto de estudo deste trabalho.

As entrevistas realizadas com a consultoria especializada responsável por realizar os serviços de modelagem de processos $\mathrm{e}$ as entrevistas com o DET.E permitiram o 
entendimento do contexto do projeto, além da análise das percepção dos envolvidos quanto a ocorrência do gap.

Percebeu-se uma coerência bem significativa entre os dados levantados no referencial teórico com os dados levantados na pesquisa. Muito dos pontos apresentados no referencial como importantes para a definição de níveis de detalhamento, sobre a influência dos diversos atores na modelagem, sobre os princípios da modelagem, foram também identificados no projeto realizado no DET.E.

Os impactos decorrentes do gap de entendimento entre o DET.E e a consultoria especializada encontrados através deste trabalho foram a falta de uniformidade dos fluxos gerados pelo mapeamento dos processos do DET.E; a influência dos entrevistados no nível de detalhamento dos processos; dificuldade no dimensionamento do projeto por parte da consultoria especializada; e falta de aderência de alguns fluxos de processos com a realidade, dificultando suas aplicações na prática. Gap este causado pela não definição no Edital de contratação da consultoria especializada do nível de detalhamento esperado na realização dos serviços; pela falta de ação da equipe durante o projeto para a validação dos níveis gerados; pela falta de conhecimento dos envolvidos no projeto quanto às especificidades dos processos do Departamento; e pela subjetividade do nível de detalhamento determinado no início do projeto entre as partes.

Apesar da identificação dos impactos causados pelo gap na realização do projeto, e que ações corretivas poderiam ter amenizado a consequiências desses impactos, foi percebido junto a consultoria especializada e junto ao DET.E que os resultados finais do projeto foram satisfatórios, cumprindo com os objetivos pré-estabelecidos pelo Departamento para a realização do projeto.

Podemos perceber, no entanto, que a minimização das consequiências do gap no estudo de caso em questão poderia ter sido alcançado pela proposta apresentado por Paim (2002) para a definição dos critérios de uniformização do nível de detalhamento de processos. Paim (2002) propõe que, primeiro, deve-se haver um referencial que explicite os níveis de detalhamento a partir dos objetivos da realização do mapeamento, sendo apresentados uma descrição e um exemplo de cada nível desejado; segundo, deve-se haver uma ação de comparação dos modelos gerados a fim de uniformizar cada nível de detalhamento; deve-se obter, por fim, um modelo para cada nível. Essa proposta permite uma flexibilidade para que os fluxos dos processos tenham um detalhamento coerente com sua realidade, sem perder uniformidade com os fluxos dos demais processos. 
Finalmente, percebe-se que o gap de entendimento entre consultorias especializadas e organizações clientes quanto ao nível ideal de detalhamento na modelagem de processos possui grande probabilidade de ocorrência em outros casos, podendo até gerar impactos mais significativos, ligados, até mesmo, diretamente com fracassos do projeto. Apesar da existência de proposta para uniformização de níveis de modelagem, percebe-se a falta de um mecanismo já testado, e por consequiência, já disseminado que lide diretamente com essa problemática. Saber lidar com esse problema permite uma maior convergência de esforço de todos os envolvidos com o projeto para o alcance dos objetivos da modelagem. 


\section{REFERÊNCIAS}

ALMEIDA, L. G. Gestão de processo e a gestão estratégica. Rio de Janeiro: Qualitymark, 2002 .

BARBARÁ, S. Análise, Modelagem e Documentação de Processos. Rio de Janeiro: Gestão por Processos: fundamentos, técnicas e modelos de implementação: foco no sistema de gestão de qualidade com base na ISSO 9000:2000, cap. 5, Qualitymark, 2006.

BEDUSCHI, A. Gestão de processos aplicada à prática: estudo de caso. Campinas: Unicamp, 2004.

BRASIL, MPOG. Guia D simplificação. Brasília, 2006.

. Lei $\mathrm{N}^{\circ}$ 8.666, de 21 de junho de 1993. Regulamenta o art. 37, inciso XXI, da Constituição Federal, institui normas para licitações e contratos da Administração Pública e dá outras providências. Disponível em: <http://www.planalto.gov.br/ccivil/Leis/L8666cons.htm> Acesso em: 15 de maio de 2009.

CORREIA, K. S. A., LEAL, F., ALMEIDA, D. A. Mapeamento de Processo: uma abordagem para análise de processo de negócio. Curitiba: XXII Encontro Nacional de Engenharia de Produção, 2002.

CRUZ, T. Sistemas, métodos \& processos: administrando organizações por meio de processos de negócio. São Paulo: Atlas, 2003.

FURNAS, Institucional, Perfil, Atuação Furnas. Disponível em: < http://www.furnas.com.br/institu_atuacao.asp>. Acesso em: 20 abr. 2009.

GOLDENBERG, M. A arte de pesquisar: como fazer pesquisa qualitativa em ciências sociais. Rio de Janeiro: Record, 1997.

GONÇALVES, J. E. L. As Empresas são grandes coleções de processos. São Paulo: RAE Revista de Administração de Empresas, v40, n 1, p. 6-19, 2000a.

Processo, que processo? Organização, Recursos Humanos e

Planejamento RAE - Revista de Administração de Empresas, v40, n 4, p. 6-19, 2000b.

GRAHAM, M., LEBARON, M.. The horizontal revolution. San Francisco: Jossey-Bass, 1994.

GROVER, V., W.R. KeTtinger, Process Think: Winning Perspectives For Business Change in the Information Age, Idea Group Inc. 2000. 
HAMMER, M., CHAMPY, J. Reengenharia: repensando a empresa em função dos clientes, da concorrência e das grandes mudanças da gerência. Rio de Janeiro: Campus, 1994.

MARAnHÃO, M., MACIEIRA, M. E. B. O Processo Nosso de Cada Dia - Modelagem de Processos de Trabalho. Rio de Janeiro: Qualitymark, 2004.

MEIRELLES, D. S. O conceito de serviços. São Paulo: Revista de Economia Política, vol. 26, no 1 (101), pp. 119-136, 2006.

MILES, I.D. The New Service Economy - The Transformation of Employment in Industrial Societies. London: Frances Pinter, 1983.

NETTO, C. A. Definindo Gestão por Processos: características, vantagens, desvantagens. São Paulo: Gestão Integrada de processos e da tecnologia da informação, Atlas, cap. 2, 2006.

PAIM, R. Engenharia de Processos: análise do referencial teórico-conceitual, instrumentos, aplicações e casos. Rio de Janeiro: Universidade Federal do Rio de Janeiro, 2002.

PAIM, R., SANTOS, D., CAULLIRAUX, H. A importância das tarefas para gestão de processos. Foz do Iguaçu: XXVII ENEGEP, 2007.

ROESCH, S. M. A. Projetos de estágio e de pesquisa em administração: guia para estágios, trabalhos de conclusão, dissertações e estudos de caso. $3^{\text {a }}$ ed. São Paulo: Atlas, 2007.

ROTONDARO, R. G. Identificação, análise e melhoria dos processos críticos. São Paulo: Gestão Integrada de processos e da tecnologia da informação, Atlas, cap. 3, 2006.

SILVA, C. L. M., BARBOSA, S. L. Estratégia, Fatores de Competitividade e Contexto de Referência das Organizações: uma Análise Arquetípica. São Paulo: RAC, v. 6, n. 3, p. 0732, 2002;

TOMANIK, E. A. O olhar no espelho: conversas sobre a pesquisa em ciências sociais. Maringá: EDUEM, 1994.

TORRES, J. B. Um modelo dinâmico de a apoio a gestão organizacional baseado na modelagem de processos utilizando componentes de software. Florianópolis: Universidade Federal de Santa Catarina, 2002. 
VALlE, R., PEIXOTO, J. A. A. Introdução: De Taylor aos nossos dias. Rio de Janeiro: Gestão por Processos: fundamentos, técnicas e modelos de implementação: foco no sistema de gestão de qualidade com base na ISSO 9000:2000, cap. 1, Qualitymark, 2006.

VILLELA, C. S. S. Mapeamento de Processos como Ferramenta de Reestruturação e Aprendizado Organizacional. Florianópolis: Universidade Federal de Santa Catarina, 2000. 


\section{APÊNDICE}

\section{TRABALHO DE CONCLUSÃO DE CURSO 1/2009}

ALUNO: VÍTOR BIZINOTO DOS S. ANJO ORIENTADOR: GUILHERME ARRUDA

TÍTULO: MODELAGEM DE PROCESSOS: GAP CONCEITUAL QUANTO AO NÍVEL IDEAL DE DETALHAMENTO DO PROCESSO

\section{QUESTIONÁRIO}

Prezado(a) Entrevistado(a),

A seguinte pesquisa faz parte da etapa de levantamento de informações para a elaboração do Trabalho de Conclusão de Curso de Administração de Empresas da Universidade de Brasília.

O presente trabalho tem por intuito estudar um problema que ocorre com frequiência na prestação de serviços de Modelagem de Processos: o Gap de entendimento entre consultorias especializadas e organizações clientes quanto ao nível ideal de detalhamento na modelagem de processos. Em diversas ocasiões, pelo o não alinhamento entre os envolvidos no projeto quanto ao nível de detalhamento desejado, os serviços de modelagem não conseguem satisfazer a organização cliente, pois ora o processo fluxogramado oculta informações, ora excede a quantidade de informações necessárias.

Sendo assim, esse trabalho tem como objetivo identificar as causas e os impactos do GAP no projeto de Modelagem e Redesenho de Processos realizado no Departamento de Telecomunicações de Furnas - DET.E através da percepção dos envolvidos no projeto.

Gostaríamos, portanto, de sua colaboração para o preenchimento do questionário (pág. 2) com o intuito de coletarmos suas percepções referentes ao tema apresentado. As perguntas estão em formato aberto para que se tenha a possibilidade de uma livre reposta para cada questão.

Dede já agradecemos sua colaboração com o nosso trabalho.

Atenciosamente,

Vítor Bizinoto dos S. Anjo 


\section{QUESTÕES}

1- No projeto desenvolvido no âmbito do Departamento de Telecomunicações - DET.E de Furnas, cujo objeto foi a "Prestação de Serviços de Consultoria para Mapeamento e Modelagem dos Processos do Departamento de Engenharia de Telecomunicações de FURNAS - DET.E”, como foi percebida a existência do GAP?

2- Segundo suas percepções, quais foram os principais motivos para que ocorresse o GAP no projeto de mapeamento e modelagem de processos do DET.E? (Os motivos podem estar relacionados a todas as etapas do projeto, desde sua definição, negociação, contratação, execução - Mapeamento e modelagem dos processos -, implementação da nova situação e avaliação de resultados).

3- Segundo suas percepções, quais foram os principais impactos decorrentes do GAP no projeto de mapeamento e modelagem de processos do DET.E? (Os impactos podem estar relacionados a todas as etapas do projeto, desde sua definição, negociação, contratação, execução - Mapeamento e modelagem dos processos -, implementação da nova situação e avaliação de resultados).

4- As motivações da contratação do serviço de Mapeamento e Modelagem de Processos estavam bem claras entre os envolvidos do projeto? Quais foram essas motivações?

5- Por se tratar de uma organização pública, quais foram as premissas adotadas para a elaboração do Termo de Referência por parte de FURNAS para a contratação do serviço? Em sua opinião, as pessoas envolvidas na elaboração das especificações técnicas dos serviços possuem conhecimento sobre técnicas e metodologias de modelagem de processos?

6- Como se deu a definição do nível do detalhamento na modelagem de processos? (fatores, premissas, técnicas etc.)

7- Houve, por parte da consultoria especializada, um esforço no esclarecimento da metodologia que seria utilizada, demonstrando de alguma forma, os resultados a serem atingidos no fim do projeto?

8- A forma como a qual os processos organizacionais foram representados ao fim do projeto atingiu as expectativas de FURNAS, conforme estabelecido na concepção do projeto? 
9- Ocorreu algum detalhamento diferenciado para alguns tipos de processos devido ao grau de competência (especialização) dos seus executores? Quais foram essas diferenças? Essas diferenças no detalhamento foram propositais?

10- Ocorreu algum detalhamento diferenciado para alguns tipos de processos devido ao grau de complexidade das atividades desempenhadas pelo DET.E? Quais foram essas diferenças? Essas diferenças no detalhamento foram propositais? 